\title{
EphB2 Tyrosine Kinase-Dependent Forward Signaling in Migration of Neuronal Progenitors That Populate and Form a Distinct Region of the Dentate Niche
}

\author{
Timothy Catchpole and Mark Henkemeyer \\ Department of Developmental Biology and Kent Waldrep Foundation Center for Basic Research on Nerve Growth and Regeneration, University of Texas \\ Southwestern Medical Center, Dallas, Texas 75390-9133
}

\begin{abstract}
The dentate gyrus (DG) is one of two areas in the mature brain where stem cells reside to continuously produce new neurons throughout adulthood. While much research has focused on the DG for its roles in adult neurogenesis, little is known regarding how this key region of the brain initially develops to form its distinct architecture. We show here that the murine EphB2 receptor tyrosine kinase is critical for embryonic/postnatal development of a specific region of the DG known as the lateral suprapyramidal blade (LSB). Intracellular truncation and point mutants demonstrate that EphB2 catalytic activity is essential for LSB formation. This is consistent with expression of EphB2 in nestin-positive neural progenitor cells that migrate medially from the lateral ventricle dentate notch neuroepithelium to populate the tertiary matrix and form the DG near the midline of the brain. Animals lacking ephrin-B1 recapitulate loss of the receptor and show that this molecule acts as the ligand to stimulate EphB2 forward signaling and direct migration of the neural progenitors into the dorsal compartment of the tertiary matrix and form the LSB. Immunoreactivity against the extracellular matrix protein Reelin in a region directly above the developing LSB is dramatically reduced when EphB2 forward signaling is disrupted. Together, these results indicate ephrin-B1 interacting with EphB2 controls the migration of dentate progenitor cells into the dorsal half of the developing DG, perhaps in part by affecting Reelin expression in a key compartment directly above the LSB.
\end{abstract}

\section{Introduction}

The subgranular zone (SGZ) of the dentate gyrus (DG), located in the hippocampus, produces neural progenitors in the adult that migrate a short distance and differentiate into granule cell neurons (Abrous et al., 2005; Zhao et al., 2008). The dentate stem/progenitor cells in the SGZ reside immediately under the mature granule cell layer and can be distinguished by the expression of markers such as nestin and glial fibrillary acidic protein (GFAP) (Alvarez-Buylla et al., 2002; Doetsch, 2003). These cells divide to self-renew and to produce rapidly amplifying progenitor cells, the latter of which become marked by the expression of Doublecortin (DCX). The DCX-positive cells further differentiate and migrate into the granule layer, where they begin to express markers associated with mature neurons and extend mossy fiber axons and dendrites to integrate and become a functional part of

\footnotetext{
Received Dec. 6, 2010; revised June 13, 2011; accepted June 13, 2011.

Author contributions: T.C. and M.H. designed research; T.C. performed research; T.C. and M.H. analyzed data; T.C. and M.H. wrote the paper.

This work was supported by the NIH (R01 MH66332). We thank Steve Kernie for the nestin-eGFP transgenic mice, Alice Davy and Phil Soriano for the ephrin-B $1{ }^{\text {loxP }}$ conditional mutant mice, Albee Messing for GFAP-cre transgenic mice, Jamey Marth for Synapsin-cre transgenic mice, Joachim Herz for the Reelin antibody, Franny Prince for genotyping, and Stacey Mohammadie for technical assistance.

The authors declare no competing financial interests.

Correspondence should be addressed to Dr. Mark Henkemeyer, Department of Developmental Biology and Kent Waldrep Foundation Center for Basic Research on Nerve Growth and Regeneration, University of Texas Southwestern Medical Center, 6000 Harry Hines Boulevard, Dallas, Texas 75390-9133. E-mail: mark.henkemeyer@ utsouthwestern.edu.

DOI:10.1523/JNEUROSCI.6349-10.2011

Copyright $\odot 2011$ the authors $\quad 0270-6474 / 11 / 3111472-12 \$ 15.00 / 0$
}

the hippocampal circuitry (van Praag et al., 2002; Zhao et al., 2006; Kee et al., 2007). Given the importance of the DG for learning and memory (Abrous et al., 2005; Zhao et al., 2008; Deng et al., 2010; Li and Pleasure, 2010), it is vital that we understand the molecules that contribute to adult neurogenesis as well as those that lead to the initial formation of this stem cell niche that occurs during late embryonic and early postnatal development.

One group of molecules that participate in stem cell biology are the Eph receptor tyrosine kinases and their membraneanchored ephrin ligands. In the adult DG, EphB1 and EphB2 are expressed on SGZ stem/progenitor cells and analysis of EphB1 ${ }^{-1-}$ mutants revealed $\sim 50 \%$ reduction in the number of early staged nestin-positive cells (Chumley et al., 2007). Loss of EphB1 expression was also found to disrupt the organization of the SGZ neurogenic niche, as stem/progenitor cells in the mutant brains showed abnormal polarity and their cell bodies were often inappropriately located in the granule cell and molecular layers. However, loss of EphB1 alone did not actually alter the number of mature granule cell neurons, as the volume of the DG was relatively normal in these mice. In contrast, when expression of both the EphB1 and EphB2 receptors was eliminated in compound mutants, the adult DG exhibited a drastic decrease in volume, indicating a greatly reduced number of mature granule neurons.

While the above study implicates EphB1 and EphB2 in adult neurogenesis, these receptors are also expressed in the earliest SGZ progenitor cells as they migrate during development and form the DG. We show that EphB2 tyrosine kinase-dependent forward signaling is vital for the early migration of the SGZ pro- 
genitor cells that form a specific subregion of the DG known as the lateral suprapyramidal blade (LSB). We further show ephrin$\mathrm{B} 1$, acting as the ligand, controls the early migration of these SGZ progenitor cells to form the LSB, and find that ephrin-B1stimulated EphB2 forward signaling is important for the normal expression of Reelin in this subcompartment of the DG. The data suggest complex interplay between EphB forward signaling and Reelin signaling in the migration of neuronal precursors in the developing brain.

\section{Materials and Methods}

Mice. Mice used in this study included EphB2- $2^{-}$protein-null, EphB2 lacZ C-terminal truncation (Henkemeyer et al., 1996), EphB2 ${ }^{\mathrm{K} 661 \mathrm{R}}$, $E p h B 2^{\Delta \mathrm{VEV}}, E p h B 2^{\mathrm{KVEV}}$ point mutants (Genander et al., 2009), nestineGFP (Yu et al., 2005), ephrinB1 ${ }^{\text {loxP }}$ (Davy et al., 2004), GFAP-cre (Zhuo et al., 2001), and Synapsin-cre (Zhu et al., 2001). These mice were maintained on a CD1 background and housed in the Animal Resource Center at the University of Texas Southwestern Medical Center at Dallas. All experiments conducted on animals were performed according to protocols approved by the Institutional Animal Care and Use Committee.

Immunofluorescence of brain sections. Brain sections were obtained from both adult mice ( $8-10$ weeks old) and embryonic mice. Adult mice were anesthetized by ketamine/xylazine, and then transcardially perfused with $4 \%$ paraformaldehyde (PFA) in PBS. Brains were removed and fixed overnight in $4 \%$ PFA. Coronal sections $(40 \mu \mathrm{m})$ were collected on a vibratome from agarose-embedded brains and placed in a series of nine wells in PBS with $0.1 \%$ sodium azide. Immunofluorescence (IF) was performed on adult sections by incubating free-floating sections with primary antibodies overnight at $4^{\circ} \mathrm{C}$. Donkey secondary antibodies conjugated with $\mathrm{Cy} 2, \mathrm{Cy} 3$, or $\mathrm{Cy} 5$ were incubated with the free-floating sections for $8 \mathrm{~h}$ at room temperature (RT).

For embryonic sections, pregnant female mice were killed using $\mathrm{CO}_{2}$ and embryos were removed and anesthetized by lowering body temperature on ice. Embryos were transcardially perfused with $4 \%$ PFA in PBS. The heads were removed and fixed in $4 \%$ PFA for $4 \mathrm{~h}$, then sunk in $30 \%$ sucrose in PBS. Coronal sections $(14 \mu \mathrm{m})$ were prepared on a cryostat and dried overnight on slides. For IF, primary antibodies were placed on slides overnight at $4^{\circ} \mathrm{C}$. Secondary antibodies were placed on slides for $3 \mathrm{~h}$ at RT.

BrdU was injected intraperitoneally into pregnant females at stage E18 at a concentration of $200 \mathrm{mg} / \mathrm{kg}$. Two hours postinjection, the female was killed using $\mathrm{CO}_{2}$ administration and the embryos removed and transcardially perfused with $4 \%$ PFA. Cryostat sections were dried on slides, postfixed in $1 \% \mathrm{PFA}$ in $\mathrm{PBS}$ for $10 \mathrm{~min}$ at RT, placed in $2 \mathrm{~N} \mathrm{HCl}$ in PBS for $30 \mathrm{~min}$ at $37^{\circ} \mathrm{C}$, then placed in $0.1 \mathrm{~m}$ borax, $\mathrm{pH} 8.5$, for $10 \mathrm{~min}$ at RT. The sections were then exposed to primary and secondary antibodies.

Primary antibodies used in this study were rabbit anti-green fluorescent protein (GFP, 1:500; Invitrogen), guinea pig anti-GFAP (1:500; Advanced Immunochemical), goat anti-DCX (1:500; Santa Cruz Biotechnology), mouse anti-NeuN (1:1000; Millipore Bioscience Research Reagents), rat anti-5-bromo-2-deoxyuridine (BrdU, 1:500; Abcam), goat anti-EphB2 (1:500; R \& D Systems), goat anti-ephrin-B1 (1:500; R \& D Systems), goat anti-Sox2 (1:1000; Santa Cruz Biotechnology), and mouse G10 anti-Reelin (1/500) (de Bergeyck et al., 1998). Other staining techniques used included Nissl stains (Poly Scientific) and fluorescent neurotrace (1:1000; Invitrogen).

Volume estimation. Stereologic volume estimates were acquired by analyzing every ninth section spanning the hippocampus from bregma -0.82 to $-4.04 \mathrm{~mm}$, spanning the length of the DG. Sections were stained with Nissl. Measurements were performed using Stereo Investigator 9 software (MBF Bioscience) and an Olympus BX51 microscope. Volumes were estimated according to the Cavalieri principle. To define the lateral and medial suprapyramidal blade bins for each section, the total length of the suprapyramidal blade from tip to the back point of the crest was measured. This length was bisected to produce two bins of equivalent length. The same method was used to define the lateral and medial infrapyramidal blade bins.

Cell quantification. GFP-positive cells were quantified using the optical fractionator method, where every ninth section throughout the hip- pocampus is examined. The DG was subdivided into four bins using the same method as the volume estimation protocol. GFP-positive cells in the subgranular zone were labeled with $\mathrm{DAB}$ and counted using an Olympus BX51 microscope. Because every ninth section was examined, the total number of GFP-positive cells counted was multiplied by nine to give an estimate of total number of cells per bin.

BrdU-labeled cells at E18 were quantified by imaging a $20 \times$ field of view in equivalent coronal sections. The embryonic DG was divided into dorsal and ventral halves, and BrdU-positive cells quantified in each half.

Statistical analysis. Data illustrated in graphs represent the mean of repeated observations. Error bars represent the SEM of those observations. All statistical analysis was performed with Prism 4 (GraphPad Software).

\section{Results}

\section{EphB2 forward signaling defines a subcompartment of the DG}

Previous analysis of EphB1 ${ }^{-/-}$; EphB2 $2^{-/-}$compound-null adult mice revealed a large reduction in volume of the entire DG as determined by measurement of the mature granule cell layer, and that this is associated with a diminished number of nestinpositive neural progenitors throughout the SGZ (Chumley et al., 2007). However, while the EphB1 ${ }^{-1-}$ single mutant did exhibit a reduction in nestin-positive cells throughout the SGZ, an obvious reduction in DG volume was not observed. This suggests that EphB1 and EphB2 receptors may share common overlapping functions in the DG, or perhaps have independent but complementary activities. To investigate potential roles for EphB2 alone, we examined the DG of adult EphB $2^{-1-}$ single mutant adult mice (8-10 weeks old) in Nissl stains of coronal vibratome sections and observed a fully penetrant reduction compared with wildtype (WT) littermates in the volume of the lateral portion of the upper granule layer of the DG, an area known as the LSB (Fig. $1 A$, asterisk). This reduction in the LSB is specific for the loss of EphB2 expression and was not observed in other Eph single null mutants analyzed, including EphB1 ${ }^{-1-}, E p h B 3^{-1-}, E p h B 6^{-1-}$, or EphA4 $4^{-1-}$ mice (data not shown).

We also analyzed the EphB2 ${ }^{\text {lacz }} \mathrm{C}$-terminal truncation mutation to determine whether the reduced LSB is due to loss of forward signaling. The EphB2 lacZ allele produces a protein in which the majority of the intracellular segment of EphB2 is replaced by an in-frame fusion to $\beta$-galactosidase ( $\beta$ gal), allowing it to be expressed on the cell surface and able to bind ephrins on adjacent cells to stimulate reverse signaling (Henkemeyer et al., 1996). However, as the EphB2- $\beta$ gal fusion protein lacks the tyrosine kinase catalytic domain and PDZ binding motif, it is unable to transduce forward signals that require these intracellular sequences. Examination of the DG in adult EphB2 ${ }^{\text {lacZ/lacZ }}$ mice showed a similar fully penetrant reduction in numbers of granule cell neurons specifically in the LSB (Fig. $1 \mathrm{~A}$, asterisk). This demonstrates that the EphB2 intracellular domain is vital for normal appearance of mature granule cell neurons in the LSB.

To quantify this defect, we first measured the total volume of the DG in the EphB2 mutant mice using stereological analysis. While there was a trend toward a slightly smaller DG in the $E p h B 2^{-1-}$ and EphB2 ${ }^{\text {lacZ/lacZ }}$ mutants, there was no significant difference in total DG volume compared with WT (Fig. $1 B$ ). As loss of EphB2 appeared to specifically affect the LSB while leaving the remainder of the DG relatively intact, we stereologically measured the volume of four separate areas within the DG: the LSB (bin 1), the medial suprapyramidal blade (bin 2), the medial infrapyramidal blade (bin 3), and the lateral infrapyramidal blade (bin 4) (Fig. 1C). Stereologic volume determination revealed that the LSB in the EphB2 $2^{-1-}$ and EphB2 $2^{\text {acZ/lacZ }}$ mutants demon- 
strated a $40 \%$ reduction in volume compared with WT (Fig. 1D). The other areas of the DG showed no significant change in volume compared with WT in either $E p h B 2^{-1-}$ or EphB2 $2^{\text {lacZ/lacZ }}$ mutants, demonstrating that loss of EphB2 expression only perturbs the volume of the LSB. To represent this volumetric data another way, the proportion of total DG volume that the LSB occupies was calculated with the value for WT mice being 25\%. Using this method, the proportions of LSB volume in $E p h B 2^{-1-}$ and EphB2 lacZ/lacZ $\mathrm{mu}-$ tants were both determined to be $<20 \%$ of the total DG volume (Fig. $1 E$ ).

To search for deficits in the stem/ progenitor niche of the DG, the EphB2 mutants were crossed to a nestin-eGFP transgenic mouse (Yu et al., 2005), which labels early stage stem/progenitor cells in the SGZ. The late-stage rapidly amplifying progenitors derived from the nestinpositive cells can be identified by DCX expression. Using IF to detect both markers, the entire SGZ was well populated in WT mice with both GFP-positive early progenitors and DCX-positive late-stage progenitors, while the corresponding cells in the EphB2 $2^{-1-}$ and EphB2 $2^{\text {lacZ/lacZ }}$ mice appeared obviously reduced (Fig. $1 F$ ). Quantification of GFP-positive progenitors revealed a $35 \%$ reduction in the total numbers of early-stage progenitor cells in the EphB2 $2^{-1-}$ and EphB2 lacZ/lacZ mutants (Fig. $1 G$ ). Quantification of total GFPpositive cells in each of the four defined bins showed that a statistically significant loss of progenitors occurred in each of the four areas in EphB2 mutants (Fig. $1 H$ ). This loss was especially pronounced in the LSB as the EphB2 $2^{-1-}$ and EphB2 $2^{\text {lacZ/lacZ }}$ mutants had only $36 \%$ and $19 \%$, respectively, of the GFP-positive cells in bin 1 compared with the WT mice. By calculating the proportion of total GFP-positive cells that are located in the LSB, it was determined that the EphB2 $2^{-1-}$ and $E p h B 2^{\text {lacZ/lacZ }}$ mutants contained only $14 \%$ and $8 \%$, respectively, of the total complement of early-stage neural precursors. These data demonstrates that EphB2 forward signaling is important for normal numbers of progenitor cells throughout the dentate niche and that it is most critical for the presence of progenitors and mature granule cell neurons in the LSB.

Genetic deletion of EphB1 also resulted in an overall decrease in progenitor cell numbers throughout the DG, similar to the data presented for loss of EphB2, although without selective preference for the LSB (Chumley et al., 2007). To determine whether EphB2 shared other roles
A
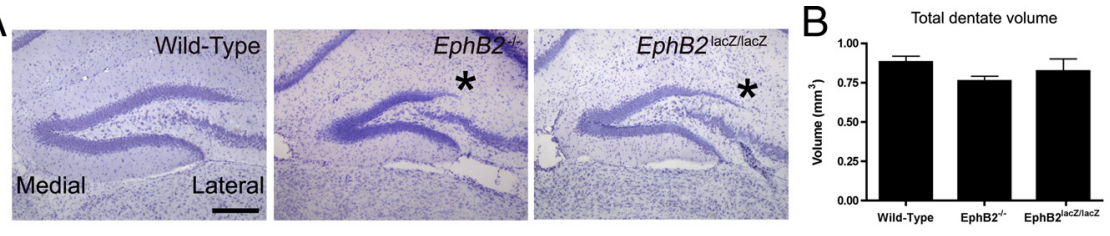

C

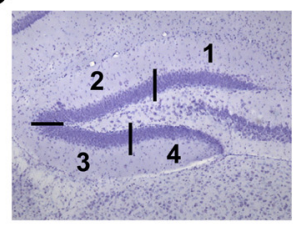

D
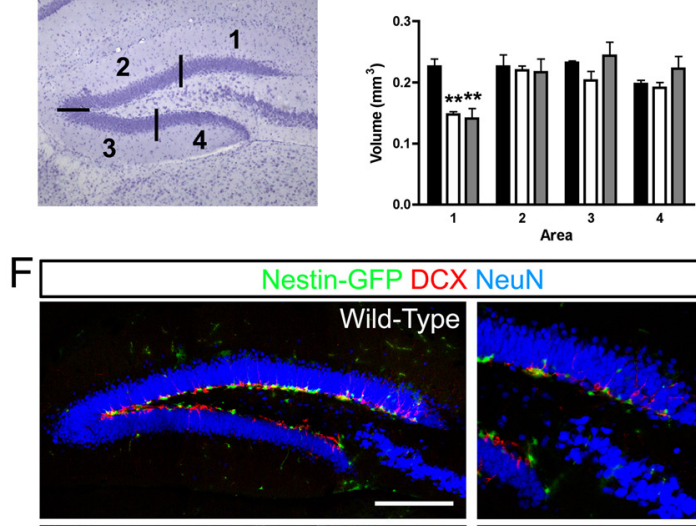

euN
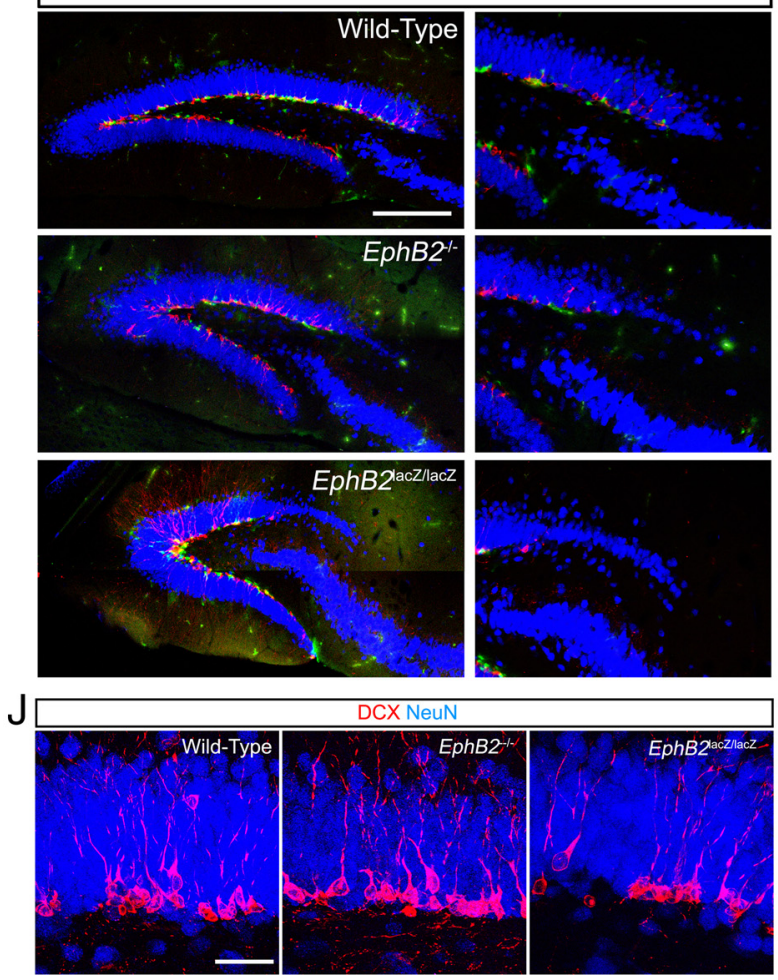

$E$

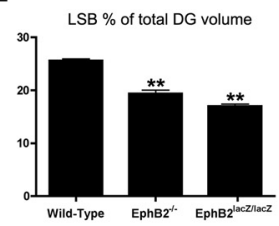

G

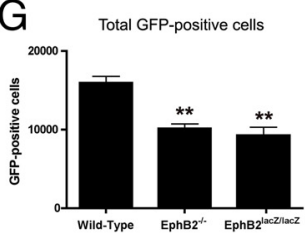

$\mathrm{H}$

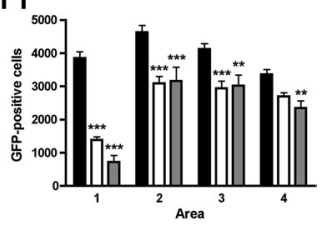

I

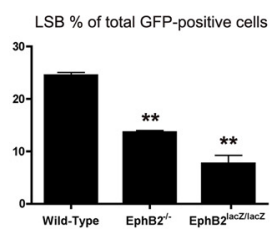

Figure 1. Loss of the EphB2 receptor leads to a reduced dentate LSB. $\boldsymbol{A}$, Nissl stains of coronal vibratome sections bisecting the hippocampus in WT, EphB2 ${ }^{-1-}$ protein-null, and EphB2 lacZ/lacz C-terminal truncation mutant adult mice (asterisk, reduced LSB). Scale bar, $200 \mu \mathrm{m}$. B, Quantification of the total dentate volume showed no significant change in overall volume in the EphB2 ${ }^{-1}$ and EphB2 ${ }^{\text {lacZ/lacZ }}$ mutants compared with WT (one-way ANOVA, Dunnett's multiple-comparison test, $n=3-4$ per group analyzed). C, The DG was subdivided into four bins for quantification purposes; LSB (area 1), medial suprapyramidal blade (area 2), medial infrapyramidal blade (area 3), and lateral infrapyramidal blade (area 4). D, Stereological quantification of the volumes within the four bins demonstrated a significant reduction in the LSB of the DG in EphB2 ${ }^{-1-}$ and EphB2 ${ }^{\text {lacz/lacz }}$ mutants (tw0-way ANOVA, Bonferroni posttests indicated significant difference in $L S B$, ${ }^{* *} p<0.01, n=3-4$ per group analyzed). $\boldsymbol{E}$, The LSB showed a significant reduction in proportion of total dentate volume in EphB2 $2^{-1-}$ and EphB2 $2^{\text {lacZ/lacZ }}$ mutants compared with WT (oneway ANOVA, Dunnett's multiple-comparison test, ${ }^{* *} p<0.01, n=3-4$ per group analyzed). $\boldsymbol{F}$, Confocal IF images of the DG from WT, EphB2 ${ }^{-1-}$, and EphB2 lacz/lacz adult mice carrying a nestin-eGFP transgene immunoreacted for GFP (green), DCX (red), and NeuN (blue). The mutants showed reduced numbers of early- and late-stage progenitors in the LSB. Scale bar, $200 \mu \mathrm{m}, 100 \mu \mathrm{m}$ in expanded view. G, Total numbers of GFP-positive progenitor cells in the DG were significantly reduced in EphB2 ${ }^{-1-}$ and EphB2 ${ }^{\text {lacZ/lacZ }}$ mutants (one-way ANOVA, Dunnett's multiple-comparison test, ${ }^{* *} p<0.01, n=3-4$ per group analyzed). $\boldsymbol{H}$, Total numbers of GFP-positive progenitors were significantly reduced in all four areas (LSB, medial suprapyramidal blade, medial infrapyramidal blade, and lateral infrapyramidal blade) of the DG in EphB2 ${ }^{-1-}$ and EphB2 lacZ/lacz mutants compared with WT (two-way ANOVA, Bonferroni posttests indicated significant differences in all areas except the lateral infrapyramidal blade of the EphB2 $^{-I-}$ mice; ${ }^{* *} p<0.01,{ }^{* * *} p<0.001, n=3-4$ per group analyzed). I, The proportion of the total GFP-positive progenitor population located in the LSB was significantly reduced in EphB2 $2^{-1-}$ and EphB2 lacz/lacz mutants (one-way ANOVA, Dunnett's multiple-comparison test, ${ }^{* *} p<0.01, n=3-4$ per group analyzed). J, Confocal IF images of the DG from WT, EphB2 ${ }^{-1-}$, and EphB2 ${ }^{\text {lacZ/lacz }}$ adult mice carrying a nestin-eGFP transgene immunoreacted for DCX (red) and NeuN (blue). The organization of DCX-positive cells was not affected by loss of EphB2. Scale bar, $35 \mu \mathrm{m}$. 
A
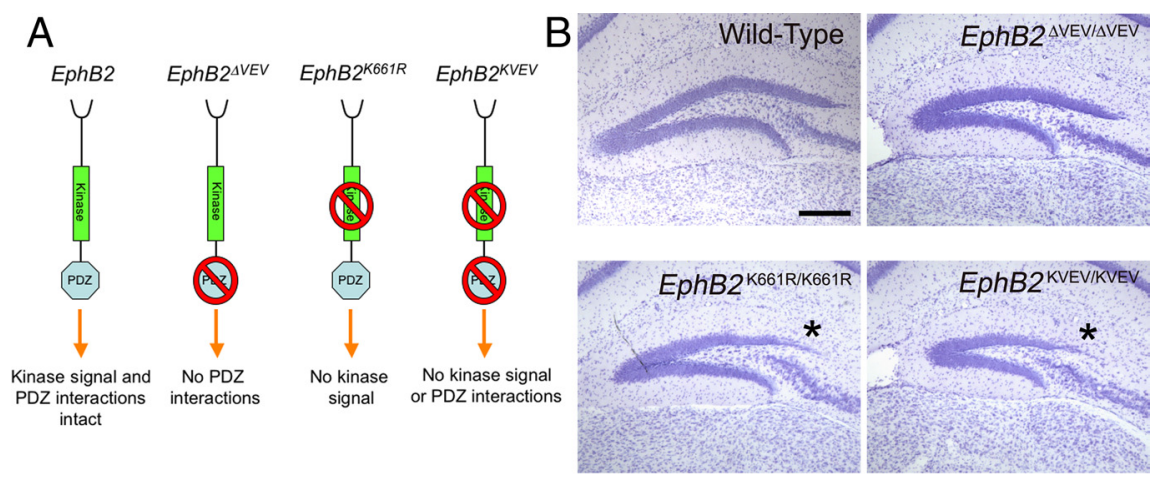

C

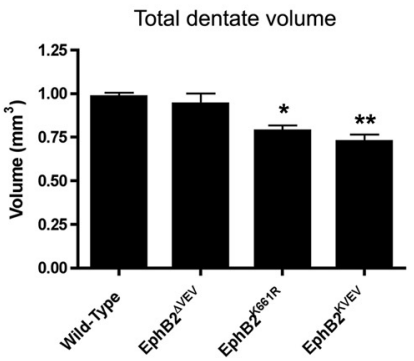

E

$\mathrm{D}$

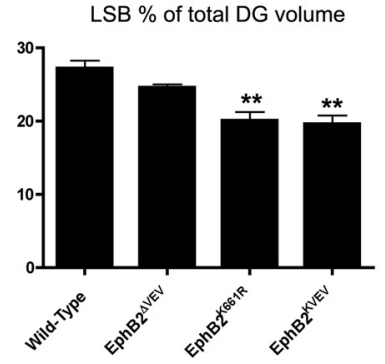

Nestin-GFP DCX NeuN
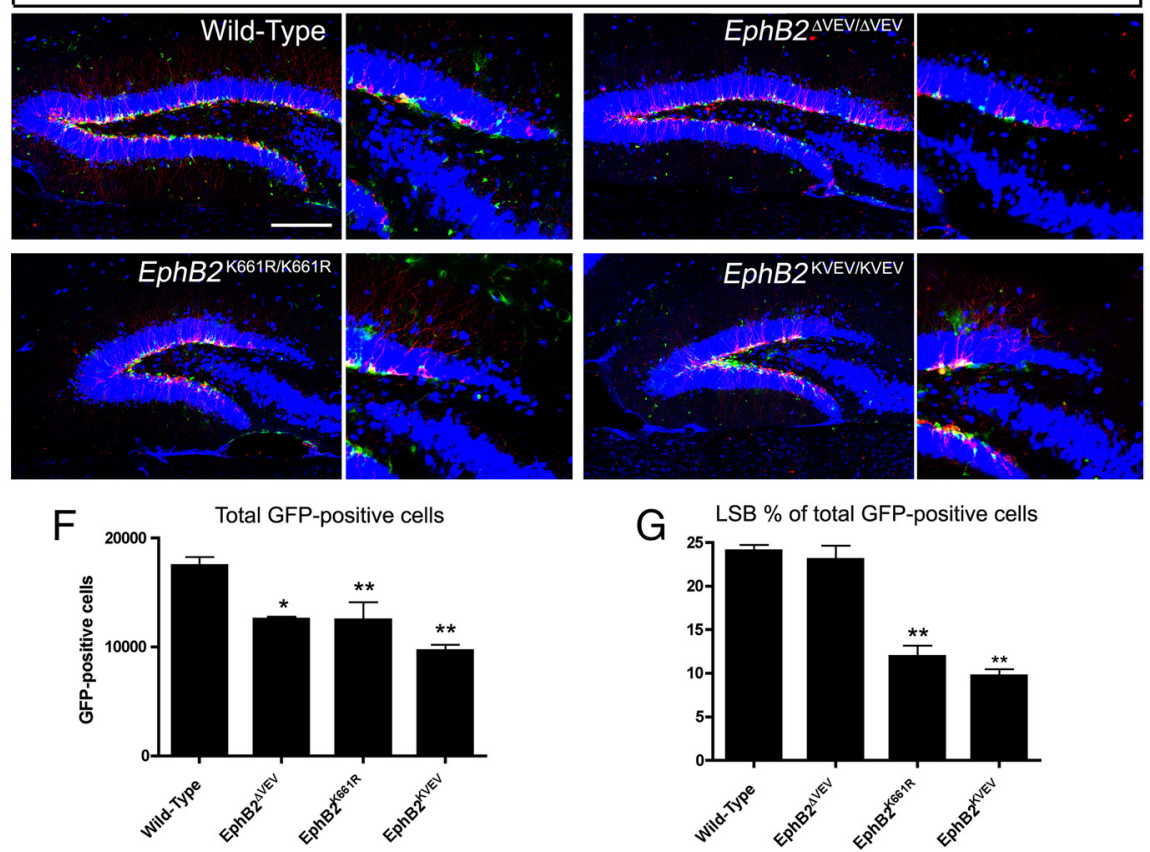

$\mathrm{G}$

LSB \% of total GFP-positive cells

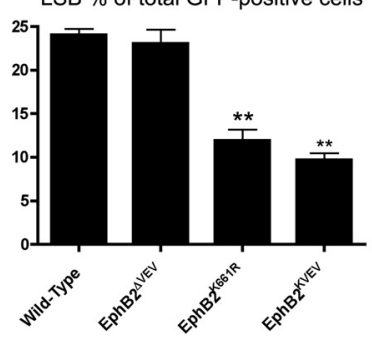

Figure 2. Loss of EphB2 tyrosine kinase catalytic activity leads to a reduced dentate LSB. $A$, Illustration of the effect on EphB2 forward signaling in the $\triangle \mathrm{VEV}, \mathrm{K} 661 \mathrm{R}$, and KVEV point mutant mice. $B$, Nissl stains of adult DGs from WT, EphB2 ${ }^{\triangle \mathrm{VEV} / \Delta \mathrm{VEV}}$, $E p h B 2^{\mathrm{K} 661 \mathrm{R} / \mathrm{K} 661 \mathrm{R}}$, and EphB2 ${ }^{\mathrm{KVEV} / \mathrm{KVEV}}$ mice (asterisk, reduced LSB; scale bar, $200 \mu \mathrm{m}$ ). $C$, Stereological quantification of the total dentate volume showed a significant reduction in mutants where catalytic activity of EphB2 is eliminated (one-way ANOVA, Dunnett's multiple-comparison test, ${ }^{*} p<0.05,{ }^{* *} p<0.01, n=3$ per group analyzed). $\boldsymbol{D}$, The LSB showed a significant reduction in proportion of total dentate volume in mutants where catalytic activity of EphB2 is eliminated (one-way ANOVA, Dunnett's multiple-comparison test, ${ }^{* *} p<0.01, n=3$ per group analyzed). $E$, Confocal IF images of the DG from WT, EphB2 ${ }^{\triangle \mathrm{VEV} / \triangle \mathrm{VEV}}$, $E P h B 2^{\mathrm{K} 661 \mathrm{R} / \mathrm{K} 661 \mathrm{R}}$, and EPhB2 ${ }^{\mathrm{KVEV} / K V E V}$ adult mice carrying a nestin-eGFP transgene immunoreacted for GFP (green), DCX (red), and NeuN (blue). Loss of EphB2 catalytic activity resulted in reduced numbers of progenitor cells in the LSB. Scale bar, $200 \mu \mathrm{m}, 100 \mu \mathrm{m}$ in expanded view. F, Quantification of total GFP-positive progenitors in the DG showed a significant reduction in EphB2 ${ }^{\triangle \mathrm{VEV} / \triangle} \triangle \mathrm{VEV}$, $E p h B 2^{\mathrm{K} 661 \mathrm{R} / \mathrm{K6} 61 \mathrm{R}}$, and EphB2 ${ }^{\mathrm{KVEV} / \mathrm{KVEV}}$ mice compared with WT (one-way ANOVA, Dunnett's multiple-comparison test, ${ }^{*} p<0.05$, ${ }^{* *} p<0.01, n=3$ per group analyzed). G, The proportion of the total GFP-positive progenitor population located in the LSB were significantly reduced in the mutants where catalytic activity of EphB2 is eliminated (one-way ANOVA, Dunnett's multiplecomparison test, ${ }^{* *} p<0.01, n=3$ per group analyzed). with EphB1, we examine the EphB2 mutant DGs for another phenotype observed in the EphB1 $1^{-1-}$ mouse. Targeted deletion of EphB1 led to disruption of the organization of the SGZ niche, as ectopic DCX-positive cells were observed in the granule cell and molecular layers of the DG (Chumley et al., 2007). The polarity and branching of the processes of the DCX-positive cells were also often abnormal. Analysis of DCX-positive progenitors in EphB2 mutants showed that the cells exhibited normal polarity and were confined to the SGZ, as in WT mice (Fig. $1 J)$. EphB1 and EphB2 thus appear to have distinct roles in the organization of the dentate SGZ.

\section{Tyrosine kinase activity of EphB2 is} vital for correct formation of the LSB The intracellular segment of EphB2 contains a number of domains that may participate in forward signaling, most notably a tyrosine kinase catalytic domain of $\sim 250$ aa and a PDZ domain binding motif at the extreme C-terminal tail. To determine whether either of these domains contributes to the formation of the LSB, the DG was examined in a number of EphB2 point mutant mice where catalytic activity and PDZ binding were selectively targeted (Fig. 2A) (Genander et al., 2009). EphB2 ${ }^{\Delta \mathrm{VEV}}$ deletes the last three amino acids of EphB2, eliminating the C-terminal PDZ-binding motif; $E p h B 2^{\mathrm{K} 661 \mathrm{R}}$ replaces the conserved lysine at position 661 in the tyrosine kinase domain with an arginine and renders the protein catalytically inactive; and $E p h B 2^{\mathrm{KVEV}} \operatorname{tar}-$ gets both the catalytic domain and PDZ binding motif of EphB2. Nissl stains of adult brains from the various mutants showed that while $E p h B 2^{\Delta \mathrm{VEV} / \Delta \mathrm{VEV}}$ mutants appeared fairly normal, both $E p h B 2^{\mathrm{K} 661 \mathrm{R} / \mathrm{K} 661 \mathrm{R}}$ and $E p h B 2^{\mathrm{KVEV} / \mathrm{KVEV}}$ mutants showed an obvious reduction in the DG that, like that observed for the protein-null and C-terminal truncation, was particularly apparent in the LSB (Fig. $2 B$, asterisks). Stereological measurements confirmed a significant reduction in total DG volume in the kinase-defective mutants, while the DG in the EphB2 $2^{\Delta \mathrm{VEV} / \Delta \mathrm{VEV}}$ mutant line did not demonstrate a significant reduction in volume compared with WT (Fig. 2C). The total volumes of the DG in the kinase-defective mutants were comparable to the EphB2 $2^{-1-}$ and $E p h B 2^{\text {lacZ/lacZ }}$ mutant lines. Focusing on the LSB, stereological analysis confirmed a significant reduction of total dentate volume in this region of the DG in the $E p h B 2^{\mathrm{K} 661 \mathrm{R} / \mathrm{K} 661 \mathrm{R}}$ and $E p h B 2^{\mathrm{KVEV} / \mathrm{KVEV}}$ mutants, but not in the EphB2 ${ }^{\triangle \mathrm{VEV} / \Delta \mathrm{VEV}}$ mutants, which were similar to WT (Fig. 

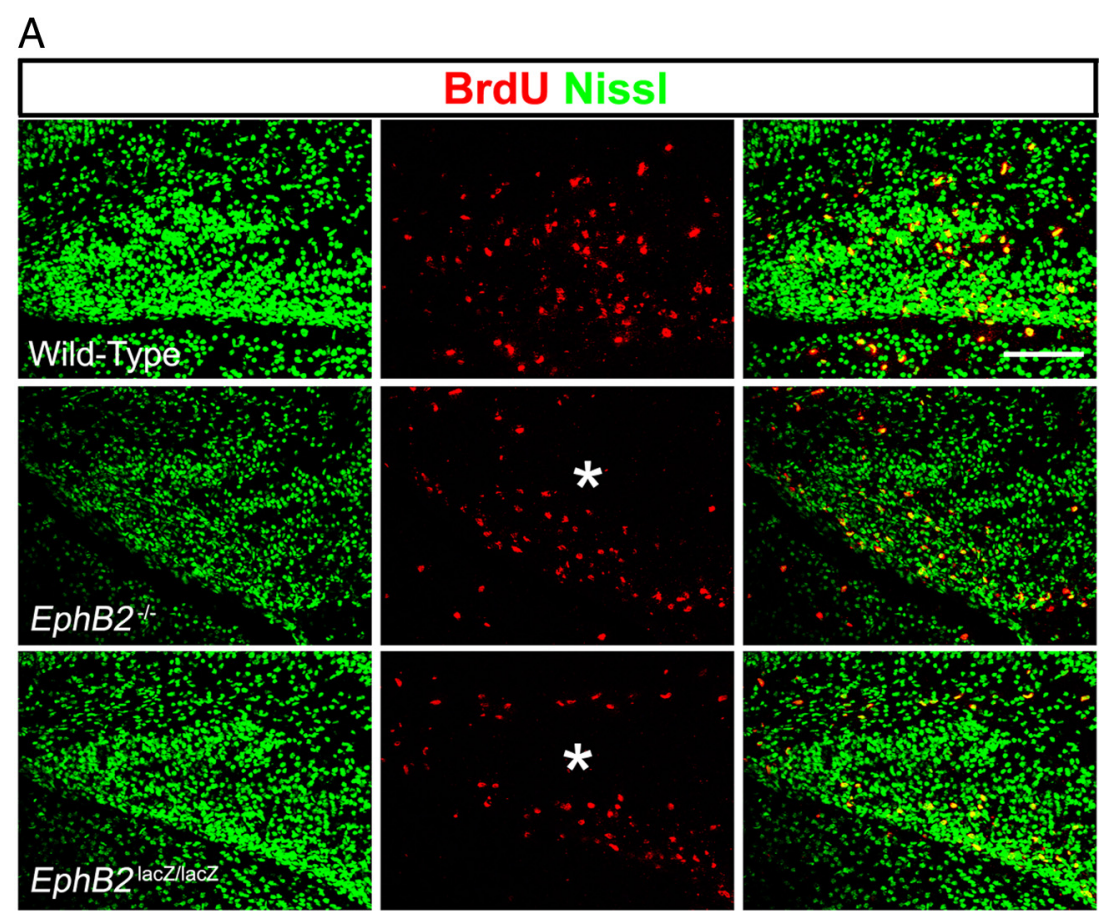

\section{B}

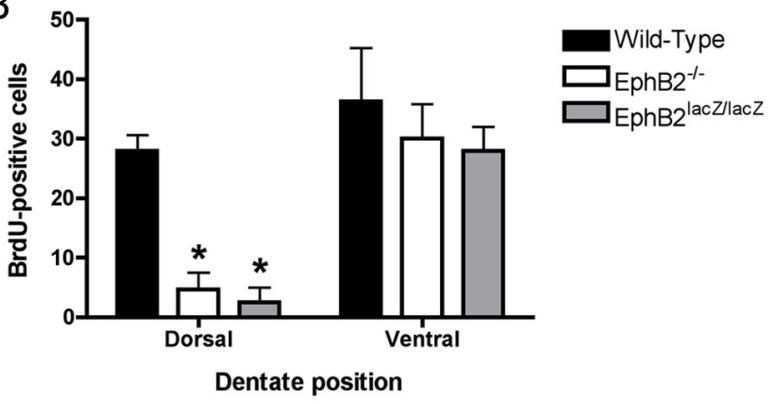

C

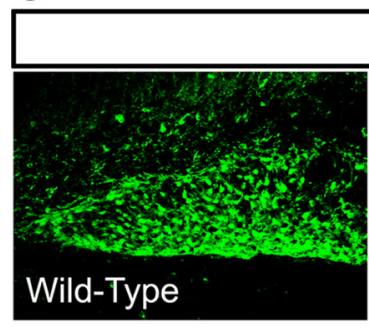

Nestin-GFP Sox2
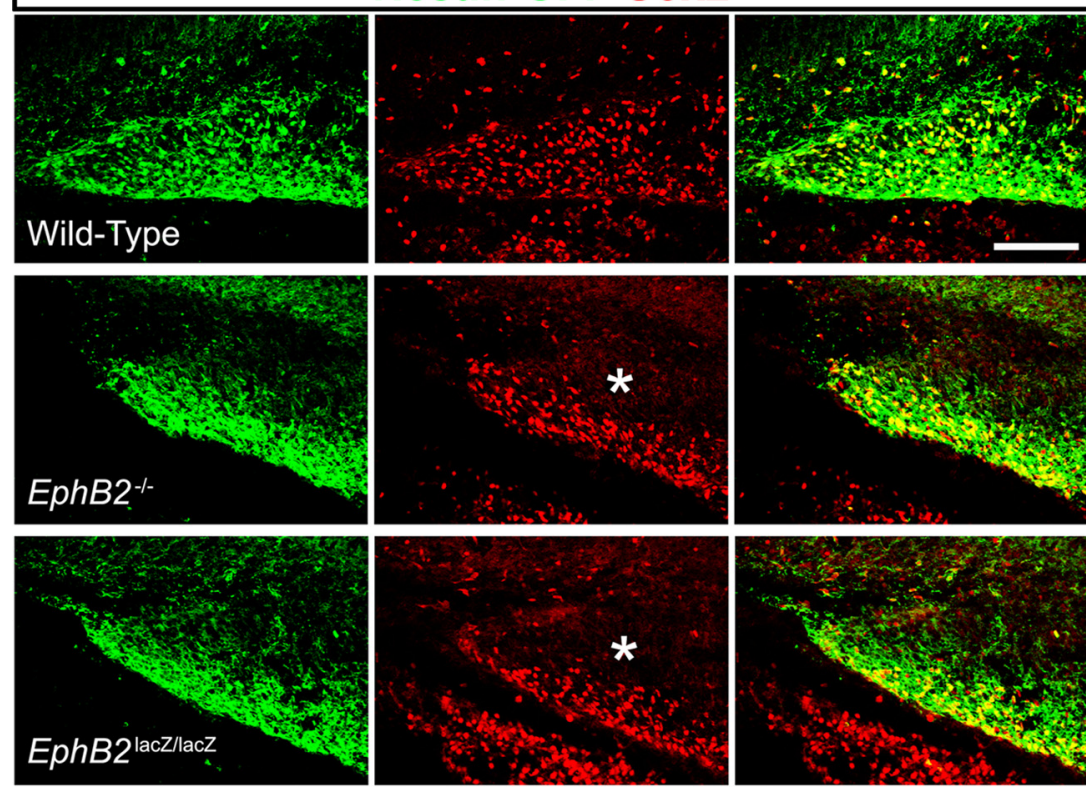

Figure 3. Loss of EphB2 disrupts embryonic development of the DG. $\boldsymbol{A}$, Confocal IF images of the early DG from WT, EphB2 and EphB2 ${ }^{\text {lacz/lacz }}$ embryonic brains collected at E18 and immunoreacted/stained for BrdU (red) and Nissl (green). Loss of EphB2 forward signaling resulted in a lack of proliferating cells in the dorsal compartment (asterisk) of the tertiary matrix. Scale bar, 100 $\mu \mathrm{m} . \boldsymbol{B}$, Quantification of BrdU-positive cells in the developing DG demonstrated a significant reduction in proliferating cells in the
2D). Together, these results indicate that the tyrosine kinase catalytic activity of EphB2 is essential for normal appearance of the LSB, while the ability of this receptor to couple to $\mathrm{PDZ}$ domaincontaining proteins is dispensable.

To determine whether EphB2 kinase activity and/or PDZ interactions are important for the neural progenitor population of the LSB, the nestin-eGFP transgene was crossed with the EphB2 signaling mutants. IF showed that the LSB in the $E p h B 2^{\Delta \mathrm{VEV} / \Delta \mathrm{VEV}}$ mutant was populated with both early- and late-stage progenitors. However, EphB2 $2^{\mathrm{K} 661 \mathrm{R} / \mathrm{K} 661 \mathrm{R}}$ and EphB2 ${ }^{\mathrm{KVEV} / \mathrm{KVEV}}$ mutants showed a drastic reduction in GFP-positive and DCXpositive cells in the LSB, similar to the EphB2 protein-null and C-terminal truncated mutants (Fig. 2E). Quantification of GFP-positive cells in the EphB2 point mutants revealed a significant loss on total GFP-positive cell numbers in both the PDZ-binding deficient and tyrosine kinase catalytically inactive EphB2 mutant lines (Fig. $2 F$ ). Interestingly, when the proportion of GFP-positive progenitors found in the LSB was quantified, the $E p h B 2^{\triangle \mathrm{VEV} / \triangle \mathrm{VEV}}$ mice showed no significant change in ratios, while the tyrosine kinase catalytically inert lines demonstrated a highly significant $50 \%$ reduction compared with WT (Fig. 2G). These data demonstrates that the tyrosine kinase activity of EphB2 is essential for a normal neurogenic cell population in the regionalized zone of the LSB, while the PDZbinding activity of EphB2 is important for the maintenance of the progenitor cell population throughout the DG.

EphB2 forward signaling in embryonic development of the DG

Formation of the DG starts during late embryogenesis as dentate precursors migrate from the neuroepithelium associated with a medial compartment of the lateral ventricular zone (the dentate notch) to the tertiary matrix, the site of DG development near the midline of the brain (Altman and Bayer, 1990a,b). The data above show that loss of EphB2 ty-

\section{$\leftarrow$}

dorsal compartment of the tertiary matrix in EphB2 $2^{-1-}$ and EphB2 ${ }^{\text {lacZ/lacZ }}$ mutants (two-way ANOVA, Bonferroni posttests, ${ }^{*} p<0.05, n=3$ per group analyzed). C, Confocal IF images of the early DG from WT, EphB2 ${ }^{-1-}$, and EphB2 lacz/lacz embryonic brains containing the nestin-eGFP transgene collected at E18 and immunoreacted for GFP (green) and Sox2 (red). Loss of EphB2 led to a reduction in GFP-positive and Sox2-positive progenitor cells in the dorsal compartment (asterisk) of the tertiary matrix. Scale bar, $100 \mu \mathrm{m}$. 
A
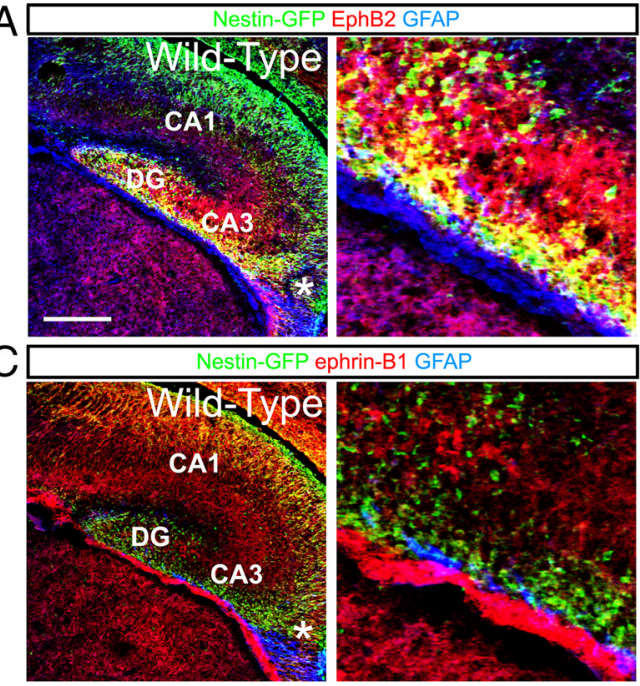

E
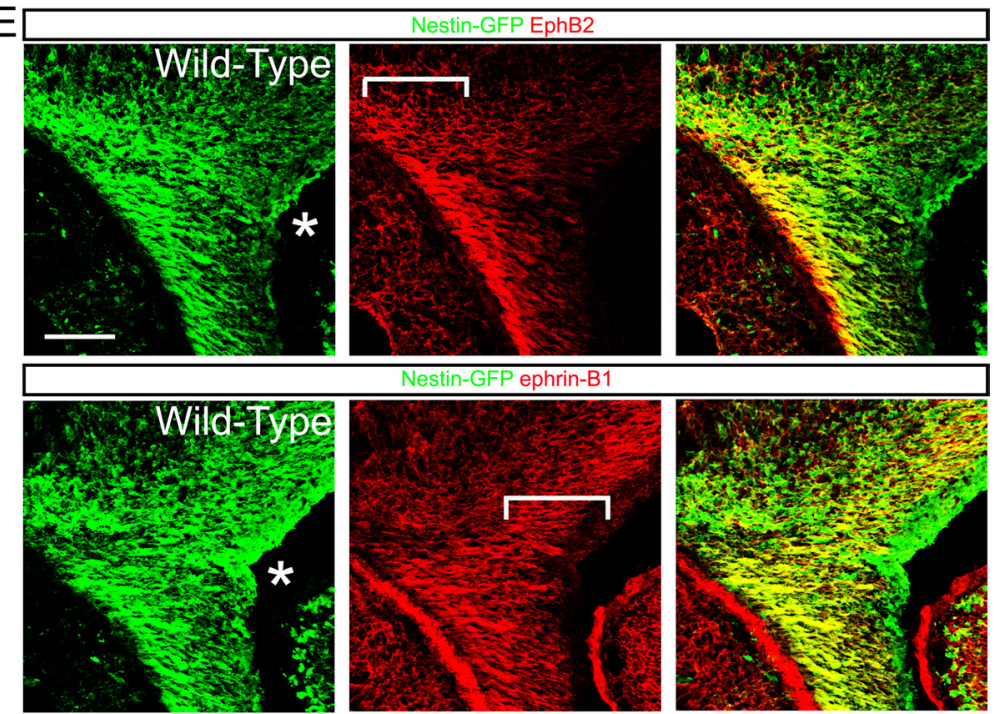

$\mathrm{F}$
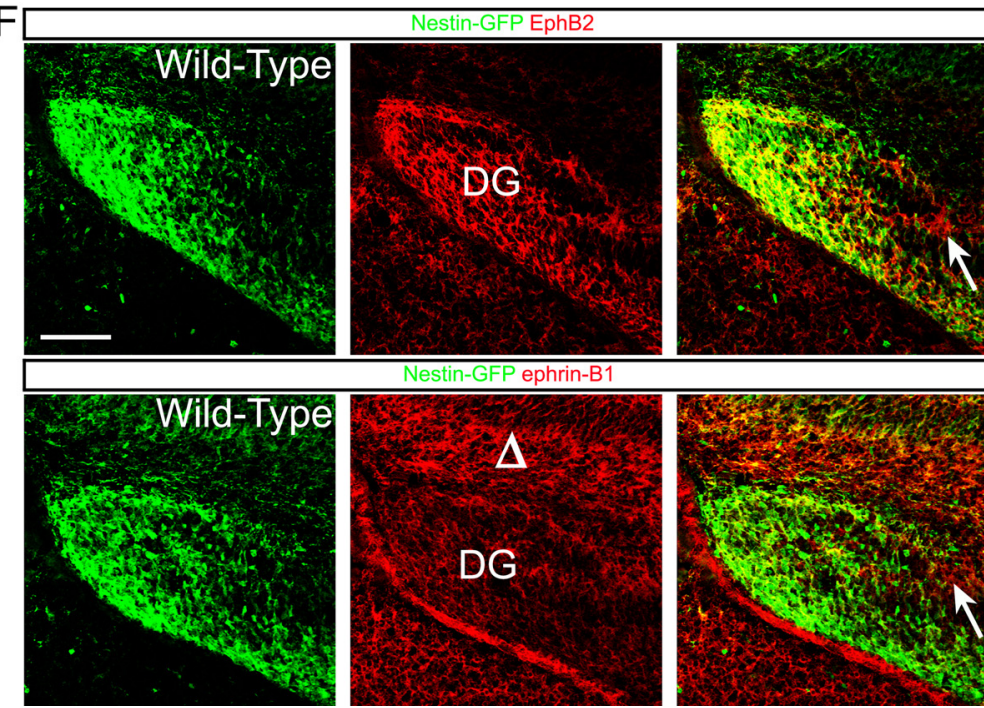

Figure 4. Expression of EphB2 and ephrin-B1 in the developing embryonic DG. $A$, Confocal IF images of a WT hippocampus containing the nestin-eGFP transgene collected at E18 and immunoreacted with EphB2 (red), GFP (green), and GFAP (blue) antibodies. EphB2 is coexpressed with GFP/GFAP (yellow/white cells) on neural progenitors migrating in a medial direction from the lateral ventricle near the dentate notch (asterisk) to the tertiary matrix where the DG forms. Scale bar, $200 \mu \mathrm{m}, 50 \mu \mathrm{m}$ in expanded view. EphB2 expression is also strong in cells forming the CA3 pyramidal layer and, to a lesser extent, in the CA1 field. $\boldsymbol{B}$, Confocal IF images of an EphB2 ${ }^{-1-}$ hippocampus containing the nestin-eGFP transgene collected at E18 and immunoreacted with rosine kinase signaling has a large impact on adult DG morphology, particularly affecting the LSB. This led us to investigate whether EphB2 signaling has a role in early development of the DG. To analyze the effects of EphB2 signaling on proliferating cells within the tertiary matrix, pregnant female mice carrying late-gestation embryos (E18) were injected with BrdU and then, following a $2 \mathrm{~h}$ labeling period, the developing DG were examined. In WT embryos, BrdU-positive cells were observed within both the upper (dorsal) and lower (ventral) halves of the tertiary matrix, the sites of the suprapyramidal and infrapyramidal blades of the DG, respectively. In contrast, BrdU-positive cells in $E p h B 2^{-1-}$ and EphB2 lacZ/lacZ mutants were observed in the lower half of the tertiary matrix, but were essentially absent from the upper half (Fig. 3A, asterisks).

$\leftarrow$

EphB2 (red), GFP (green), and GFAP (blue) antibodies. Signal for EphB2 is not observed in the mutant demonstrating specificity of the anti-EphB2 antibody. Scale bar, $50 \mu \mathrm{m}$. C, Confocal IF images of a WT hippocampus containing the nestin-eGFP transgene collected at E18 and immunoreacted with ephrin-B1 (red), GFP (green), and GFAP (blue) antibodies. Ephrin-B1 is not expressed in nestin-GFP-positive progenitors as they stream into the tertiary matrix, but it is strongly expressed in a GFAP-positive ridge directly under the migrating progenitor cells and to a lesser extent in the developing CA3 and CA1 fields (asterisk, notch). Scale bar, $200 \mu \mathrm{m}, 50 \mu \mathrm{m}$ in expanded view. $\boldsymbol{D}$, Confocal IF images of an ephrin-B ${ }^{-/ Y}$ hippocampus containing the nestin-eGFP transgene collected at E18 and immunoreacted with ephrin-B1 (red), GFP (green), and GFAP (blue) antibodies. Signal for ephrin-B1 is not observed in the GFAP-positive ridge under the migrating GFP/ GFAP-positive progenitor cells demonstrating specificity of the anti-ephrin-B1 antibody. Scale bar, $50 \mu \mathrm{m}$. $\boldsymbol{E}$, Adjacent confocal IF images of the dentate notch region from a WT animal containing the nestin-eGFP transgene collected at E18 and immunoreacted with EphB2 or ephrin-B1 (red) and GFP (green) antibodies. While EphB2 is not expressed at the dentate notch epithelium (asterisk), it becomes expressed in the nestin-GFP progenitor cells as they migrate away from the notch area toward the developing hippocampus (bracket for EphB2). Ephrin-B1 is also not expressed in the dentate notch epithelium (asterisk), but it becomes upregulated earlier than EphB2 in the nestin-GFP progenitor cells closest to the ventricular epithelium and appears to specifically mark the dentate progenitors only as they delaminate from the notch (bracket for ephrin-B1). Expression of ephrin-B1 is eventually lost from the nestin-GFP progenitors as these cells stream toward the tertiary matrix and upregulate EphB2. Scale bar, $100 \mu \mathrm{m}$. F, Adjacent confocal IF images of the dentate tertiary matrix from a WT animal containing the nestin- EGFP transgene collected at E18 and immunoreacted with EphB2 or ephrin-B1 (red) and GFP (green) antibodies. EphB2 is strongly expressed on the nestin-GFP progenitors that populate the tertiary matrix (DG), while ephrin-B1 is expressed in cells above the developing suprapyramidal blade $(\Delta)$. There also appears to be some coexpression of EphB2 and ephrin-B1 in cells at the point where the LSB will form, and these cells do not express nestin-GFP (arrows). Scale bar, $100 \mu \mathrm{m}$. 
Quantification of the BrdU-positive cells showed a significant reduction in the number of proliferating cells in the upper half of the tertiary matrix in EphB2 and EphB2 ${ }^{\text {lacZ/lacZ }}$ mutants when compared with WT, while the lower half of the tertiary matrix was unaffected (Fig. $3 B$ ). This indicates that EphB2 forward signaling is necessary for proliferating cells to populate the developing suprapyramidal blade of the dentate tertiary matrix.

We next determined whether the lack of proliferating cells in the developing suprapyramidal blade coincides with a lack of neural precursors by labeling for the nestin-eGFP transgene and another marker of neural progenitors, Sox2. IF of embryos collected at E18 showed a large population of GFP and/or Sox2-positive cells in both halves of the tertiary matrix, including the site of the developing LSB in WT animals (Fig. 3C). In contrast, EphB2 $2^{-1-}$ and EphB2 $2^{\text {lacZ/lacZ }}$ embryos had very few if any GFP or Sox2-positive cells in the upper tertiary matrix where the developing suprapyramidal blade forms (Fig. 3C, asterisks), while the lower tertiary matrix was well populated with GFP/Sox2-labeled progenitors. Interesting, while a recent study suggested that stimulation of EphB2 forward signaling in Schwann cell cultures led to increased expression/stability of Sox2 (Parrinello et al., 2010), we observed no obvious change in Sox2 IF intensity in the neural progenitors of the EphB2 $2^{-1-}$ and EphB2 $2^{\text {lacZ/lacZ }}$ mutants analyzed here in the tertiary matrix or in other regions of the developing brain. Nevertheless, our data show that EphB2 forward signaling is necessary for neural progenitors to populate the upper compartment of the tertiary matrix in the embryonic brain.

\section{EphB2 is expressed on neural} progenitors that migrate from the dentate notch and populate the tertiary matrix

Previously, we demonstrated that EphB2 is expressed on postnatal and adult nestineGFP-positive and DCX-positive progenitor cells within the SGZ of the dentate gyrus (Chumley et al., 2007). We examined the late-stage embryonic hippocampus to determine whether EphB2 was also expressed on the earliest progenitor cells that originally populate the DG. As shown in Figure $4 A$, IF at E18 determined that EphB2 is expressed on the progenitor cells migrating from the dentate notch near the lateral ventricle (asterisk) to the tertiary matrix (DG) near the midline of the brain. There is a high level of expression of EphB2 on cells labeled with the nestin-eGFP transgene as indicated by the overlap of IF signal

A

C

D

F
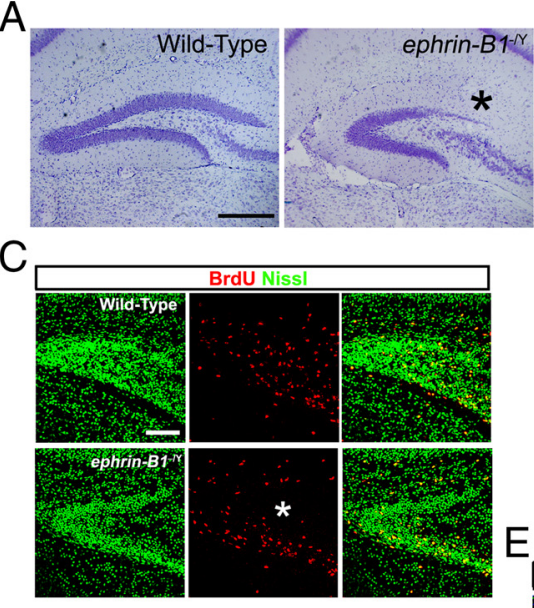

$E$
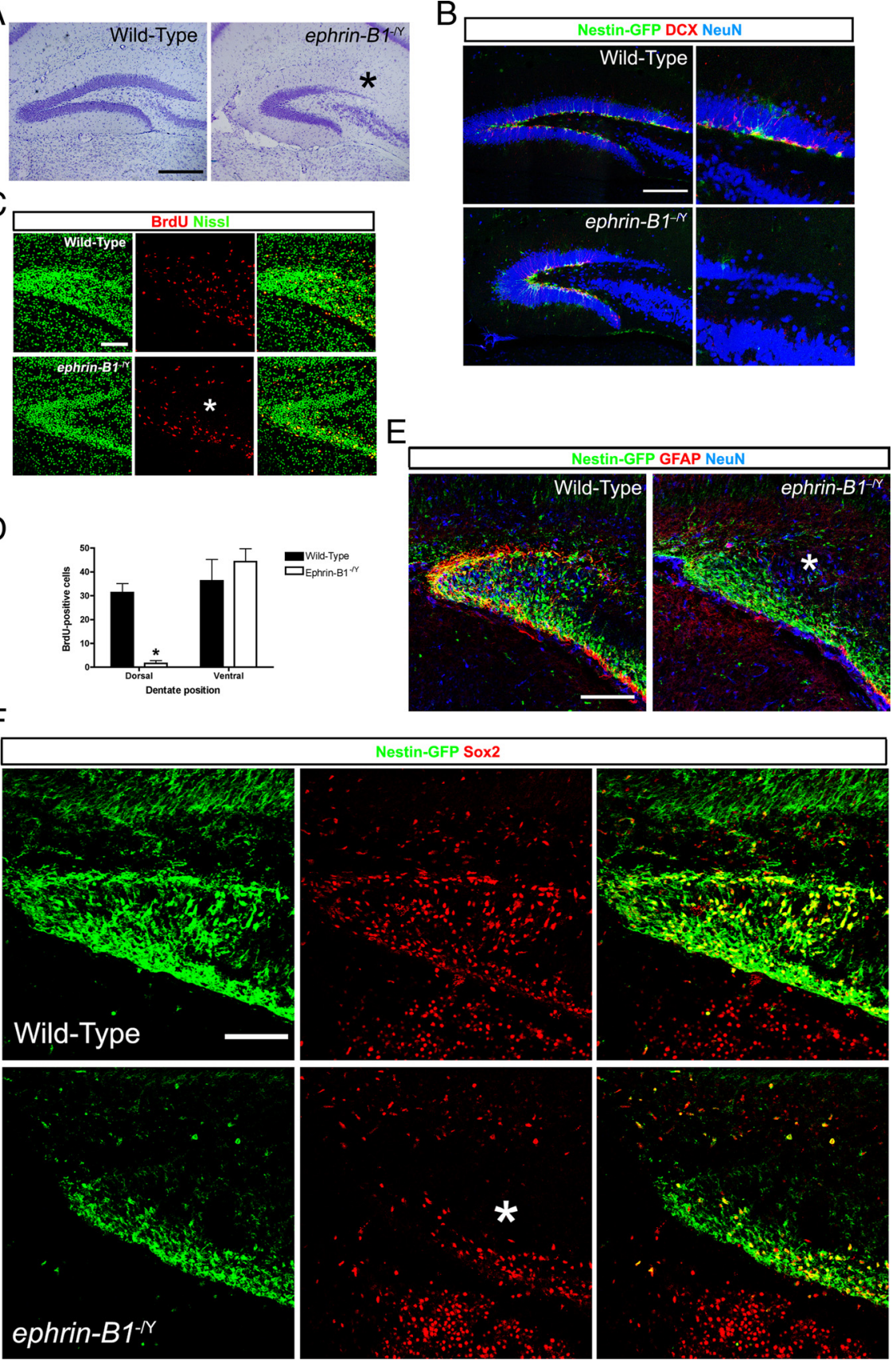

Figure 5. Loss of ephrin-B1 also leads to a reduced dentate LSB. $A$, Nissl stains of adult WT and ephrin- $B 1^{-N}$ protein-null mutants showed a thinning of the $L S B$ in the DG of mice lacking expression of ephrin-B1 in the germline. Scale bar, $200 \mu \mathrm{m}$. $\boldsymbol{B}$, Confocal IF images of the DG from WT and ephrin-B1 ${ }^{-N}$ adult mice containing the nestin-eGFP transgene and immunoreacted for GFP (green), DCX (red), and NeuN (blue). The mutant showed reduced numbers of progenitors in the LSB. Scale bar, $200 \mu \mathrm{m}, 100 \mu \mathrm{m}$ in expanded view. C, Confocal IF images of the early DG from WT and ephrin-B1 ${ }^{-N}$ brains collected atE18and immunoreacted/stained for BrdU (red) and NissI (green). Loss of ephrin-B1 resulted in reduced numbers of proliferating cells in the dorsal compartment (asterisk) of the tertiary matrix. Scale bar, 100 $\mu \mathrm{m}$. D, Quantification of BrdU-positive cells in the developing DG demonstrated a significant reduction in proliferating cells in the dorsal half of the tertiary matrixin ephrin-B ${ }^{-N}$ mice (two-way ANOVA, Bonferroni posttests, ${ }^{*} p<0.05, n=3$ per group analyzed). $E$, Confocal IF images of the DG from WT and ephrin-B1 ${ }^{-N}$ brains collected at E18 containing the nestin-eGFP transgene and immunoreacted for GFP (green), GFAP (red), and NeuN (blue). Loss of ephrin-B1 resulted in a failure of GFP/GFAP-positive progenitor cells to populate the dorsal compartment (asterisk) of the tertiary matrix. Scale bar, $100 \mu \mathrm{m}$. F, Confocal IF images of the early DG from WT and ephrin-B1 ${ }^{-N}$ brains collected at E18 containing the nestin-eGFP transgene and immunoreacted for GFP (green) and Sox2 (red). Loss of ephrin-B1 also resulted in a failure of Sox2-positive progenitor cells to populate the dorsal compartment (asterisk) of the tertiary matrix. Scale bar, $100 \mu \mathrm{m}$.

(Fig. 4A, yellow), as well as on cells forming the CA3 pyramidal layer and, to a lesser extent, the CA1 area (Fig. $4 A$, red). Interestingly, EphB2 is not expressed on GFP-positive stem/progenitor cells lining the ventricle that give rise to cortical neurons (Fig. $4 \mathrm{~A}$, 
A
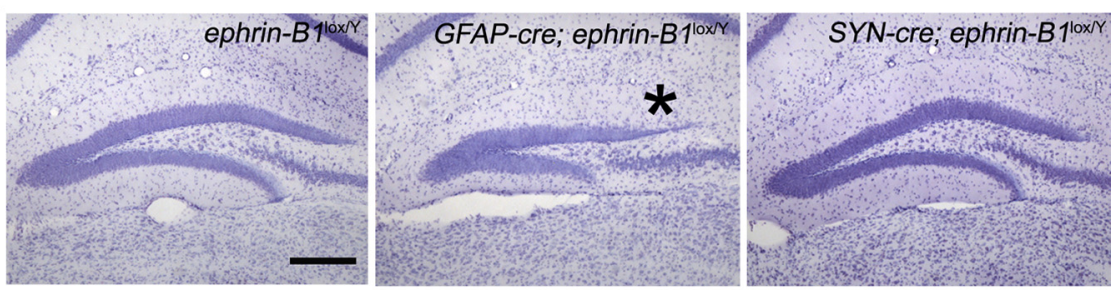

B

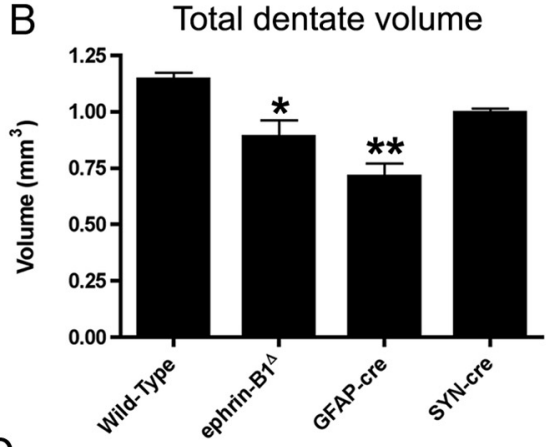

C LSB \% of total DG volume ${ }^{30} 7$
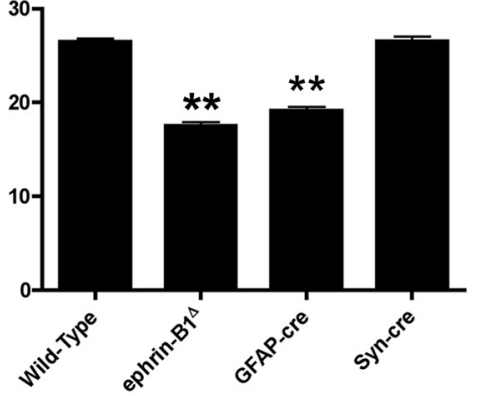

$0^{8 p^{p^{4}}}$
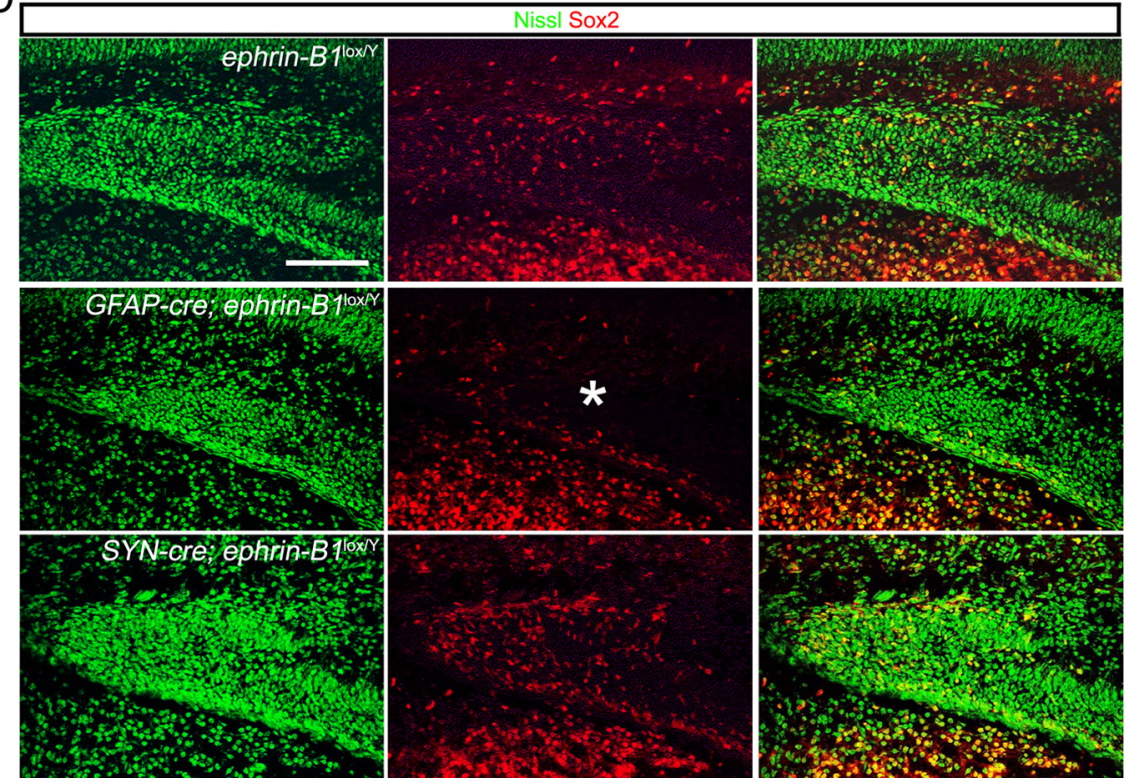

Figure 6. Deletion of ephrin-B1 with conditional Cre drivers replicates the reduced LSB phenotype. $A$, Nissl stains of adult DG from ephrin-B $1^{\mathrm{lox} / Y}$, GFAP-cre; ephrin-B1 ${ }^{\mathrm{lox} / Y}$, and Synapsin-cre; ephrin-B $1^{\mathrm{lox} / Y}$ mice. Thinning of the LSB (asterisk) was observed only in the $G F A P$-cre; ephrin-B $1^{\mathrm{lox} / \mathrm{T}}$ mice. Scale bar, $200 \mu \mathrm{m}$. $B$, Quantification of the total volume of the dentate revealed a significant reduction only in the GFAP-cre; ephrin-B $1^{\text {lox } / Y}$ mice that was similar to the germline protein-nulls (one-way ANOVA, Dunnett's multiple-comparison test, ${ }^{*} p<0.05,{ }^{* *} p<0.01, n=3-4$ per group analyzed). C, The LSB showed a significant reduction in proportion of total dentate volume only in the GFAP-cre; ephrin-B1 ${ }^{\text {lox } / Y}$ mice that was similar to the germline protein-nulls (one-way ANOVA, Dunnett's multiple-comparison test, ${ }^{* *} p<0.01, n=3-4$ per group analyzed). D. Confocal IF images of the early DG from ephrin-B1 ${ }^{\text {loxP/Y }}$, GFAP-cre; ephrin-B1 ${ }^{\text {loxP } / Y}$ and Synapsin-cre; ephrin-B1 ${ }^{\mathrm{lox} / \mathrm{V}}$ brains collected at E18 and immunoreacted for Nissl (green) and Sox2 (red). Deletion of ephrin-B1 using the GFAP-cre driver leads to a lack of Sox2-positive progenitors in the dorsal half of the tertiary matrix $(\Delta)$ (Scale bar, $100 \mu \mathrm{m})$.

green). This indicates EphB2 is specifically expressed only on the progenitor cells that leave the dentate notch and migrate in a medial direction toward the site of DG development. To confirm the specificity of the EphB2 antibody, tissue samples of EphB2 $2^{-1-}$ mutants were similarly analyzed and showed no binding in the GFP-positive progenitors (Fig. 4B).

Expression of the EphB2 ligand, ephrin-B1, was also characterized in the developing DG during late embryogenesis. IF for ephrin-B1 at E18 revealed expression of the protein in a number of areas in the developing hippocampus, including a GFAP- positive ridge that lies immediately below the migrating nestin-GFP/EphB2-positive dentate progenitors, the dentate notch (Fig. $4 C$, asterisk), and in the forming CA1 and $\mathrm{CA} 3$ areas (Fig. 4C). Interestingly, while expression of ephrin-B1 was not noted to overlap with nestin-GFP/EphB2positive cells streaming toward the tertiary matrix, there was obvious coexpression of ephrin-B1 and nestin-GFP (but not EphB2) in migrating cortical neurons originating from the lateral ventricles. Confirming the specificity of the antibody, IF for ephrin-B1 showed no signal in the GFAP-positive ridge in ephrin$B 1^{-/ Y}$ mutant brain tissue and greatly reduced signal elsewhere, likely because of some cross-reactivity of the antibody used with ephrin-B2 and/or ephrin-B3 (Fig. 4D).

Closer examination of expression within the developing hippocampus indicates that EphB2 and ephrin-B1 may interact to influence the development of the DG. EphB2 and ephrin-B1 are both expressed in fairly complex patterns in the dentate notch area (Fig. 4E). While the lateral ventricle epithelium of the dentate notch only expresses nestin-GFP (Fig. 4E, asterisk), the delaminating nestin-positive cells located immediately adjacent to the dentate epithelium were observed to coexpress ephrin-B1 (bracket for ephrin-B1 panels). As the dentate progenitor cells migrate closer toward the developing hippocampus, EphB2 appears to become coexpressed with ephrin-B1 in the nestin-GFP cells. Then, as the nestin-GFP/ EphB2/ephrin-B1 labeled progenitors migrate closer to the tertiary matrix, the coexpression of ephrin-B1 is lost and the GFP-positive cells now only express EphB2 (Fig. $4 E$, brackets). Within the tertiary matrix (Fig. 4F), EphB2 continues to be expressed at high levels in the nestin-GFP stem/progenitors that populate the developing DG, while expression of ephrin-B1 is most strongly observed in the molecular layer above the developing suprapyramidal blade (Fig. $4 F, \Delta$ ). There also appears to be a focal area of overlap of EphB2 and ephrin-B1 expression at the precise point where the LSB should form, and these cells do not appear to express nestin-GFP (Fig. $4 F$, arrows). Unfortunately, as both the EphB2 and ephrin-B1 antibodies are made in goats, we have not been able to colabel sections to better visualize this overlap of expression of these two proteins.

\section{Ephrin-B1 is also required for a normal LSB}

To determine whether ephrin-B1 is involved in development of the DG, we first analyzed an ephrin-B1 knock-out mouse obtained by crossing a floxed conditional allele (Davy et al., 2004) with a transgene that expresses Cre recombinase in the germline to delete the loxP-flanked sequences and generate a protein-null 
allele. Since this gene is $\mathrm{X}$-linked, the ephrin- $\mathrm{B} 1^{+/-}$females were then crossed to WT males to generate ephrin-B1 ${ }^{-/ Y}$ and ephrin$B 1^{+/ Y}$ hemizygous males for analysis. Nissl stains of resulting adults revealed a greatly reduced LSB in the mutant (Fig. $5 \mathrm{~A}$, asterisk). Stereological measurements of serial sections indicated a small but statistically significant reduction in total volume $\left(\mathrm{WT}=1.144 \pm 0.031 \mathrm{~mm}^{3} ;\right.$ ephrin-B1 $1^{-/ Y}=0.890 \pm 0.072 \mathrm{~mm}^{3}$; unpaired $t$ test, $p<0.05, n=4$ per group analyzed). There was, however, a highly significant reduction in the LSB as it occupied only $17.54 \pm 0.37 \%$ of the total DG volume in the ephrin-B1 ${ }^{-/ Y}$ mice, a much smaller percentage than the $26.5 \pm 0.42 \%$ measured in the WT mice (unpaired $t$ test, $p<0.001, n=4$ per group analyzed). To examine the effects of loss of ephrin-B1 on the stem/progenitor cell population of the DG, ephrin-B1 ${ }^{-/ Y}$ mice containing the nestin-eGFP transgene were generated and analyzed for both GFP and DCX-expressing cells. Like the EphB2 mutant mice, there is almost a complete loss of both early-stage and late-stage progenitors in the LSB of ephrin- $B 1^{-/ Y}$ mice, while the remainder of the DG contained an obvious complement of neural progenitors (Fig. 5B). Quantification of the total number of GFP-positive cells in ephrin-B1 ${ }^{-/ Y}$ DG revealed a trend toward fewer early-stage progenitors compared with WT (WT = $18,350 \pm 2179 ;$ ephrin- $B 1^{-/ Y}=11,170 \pm 2037$; unpaired $t$ test, $n=4$ per group analyzed). There was, however, a highly significant reduction in the percentage of GFP-positive cells within the LSB compared with the total progenitor pool $(\mathrm{WT}=24.41 \pm$ $0.96 \%$; ephrin-B1 $1^{-/ Y}=8.27 \pm 1.27 \%$; unpaired $t$ test, $p<0.001$, $n=4$ per group analyzed).

To investigate the developmental effect of loss of ephrin-B1 expression, a $2 \mathrm{~h}$ pulse of BrdU was conducted in utero at E18. The data showed that while the upper tertiary matrix of WT embryos contained a number of BrdU-positive cells, very few proliferating cells were observed in this compartment in the ephrin-B1 ${ }^{-/ Y}$ embryos (Fig. 5C, asterisk). Quantification of BrdU-positive cells showed a significant decrease in proliferating cells in the dorsal half of the tertiary matrix in ephrin-B1 ${ }^{-/ Y}$ mutants, while the numbers of proliferating cells in the ventral half were not significantly affected (Fig. 5D). Likewise, analysis of nestin-eGFP and Sox2-positive cells at E18 showed reduced numbers of neural progenitors in the developing suprapyramidal blade of ephrin-B1 ${ }^{-/ Y}$ embryos (Fig. $5 E, F$, asterisks). As with the EphB2 mutants, no obvious change in Sox2 IF intensity was noted in the remaining neural progenitors of ephrin$B 1^{-/ Y}$ mutant brains. Interestingly, GFAP expression surrounding the tertiary matrix appeared to be disrupted in the ephrin-B1 $1^{-/ Y}$ mutants, particularly in the dorsal half of the developing DG. The phenotype observed in the DG of mice lacking ephrin-B1 is very similar to mice lacking EphB2 kinase-dependent forward-signaling, demonstrating that an ephrin-B1:EphB2 signaling partnership is vital for the correct formation of the DG.

\section{Ephrin-B1 expression above the developing LSB regulates formation of the DG}

Our analysis of the expression pattern of ephrin-B1 as shown in Figure 4 suggests that ephrin-B1 is expressed in GFAP-positive cells, including a GFAP-positive ridge directly underneath the EphB2/ nestin-GFP-positive progenitor cells that are migrating toward the tertiary matrix. To investigate the activity of ephrin-B1 in GFAPpositive cells, we crossed conditional ephrin- $B 1^{\text {loxP/loxP }}$ female mice with GFAP-cre (Zhuo et al., 2001) transgenic males to eliminate ephrin-B1 expression in GFAP-positive cells while leaving it intact in other populations in male offspring. As a control, ephrin-B1 $1^{\text {loxP/loxP }}$ females were also crossed to Synapsin-cre (Zhu et al., 2001) transgenic males to delete ephrin-B1 in mature neurons. As shown in
Figure $6 A$, a reduced LSB was observed in the GFAP-cre;ephrin$B 1^{\text {loxP/Y }}$ combination (asterisk), while the Synapsin-cre;ephrin$B 1^{\text {loxP/Y }}$ brains appeared similar to the ephrin- $B 1^{\operatorname{lox} / Y}$ controls that did not receive a Cre driver. Stereological analysis of total volume of the dentate in these mice revealed a significant loss in the GFAP-cre; ephrin-B1 ${ }^{\text {loxP/Y }}$ DG compared with controls (Fig. $6 B$ ). Furthermore, the LSB was particularly affected in the GFAP-cre;ephrin-B $1^{\text {loxP/Y }}$ combination, demonstrating an equivalent reduction in proportion of total dentate volume to the ephrin-B1 ${ }^{-/ Y}$ protein-null mutants (Fig. 6C).

To determine whether the LSB reduction observed in GFAPcre;ephrin-B1 $1^{\text {loxP/Y }}$ mice was due to a developmental defect, we examined the developing DG at E18 for expression of Sox2positive progenitors (Fig. $6 \mathrm{D}$ ). The developing suprapyramidal blade in the GFAP-cre;ephrin-B1 ${ }^{\text {loxP/Y }}$ hippocampus showed a noticeable deficit of Sox2-positive progenitor cells (Fig. 6D, asterisk), demonstrating that the GFAP-cre;ephrin-B1 ${ }^{\text {loxP/Y }}$ and ephrin-B1 ${ }^{-/ Y}$ DG share a similar developmental defect. In both the Synapsin-cre;ephrin-B1 $1^{\operatorname{lox} / \mathrm{Y}}$ and ephrin- $B 1^{\operatorname{lox} \mathrm{P} / \mathrm{Y}}$ brains, this area was well populated with Sox 2 progenitor cells.

To examine in closer detail the activity of the cre drivers, we crossed a Rosa-YFP transgene into the cre backgrounds, where YFP is preceded by a stop codon flanked with loxP sites. We then examined the cre lines for YFP and ephrin-B1 expression at E18. Extensive expression of YFP was observed throughout the developing hippocampus and cortex of the GFAP-cre;ephrin-B1 ${ }^{\text {loxP/Y }}$ mice, indicating a number of cell populations contained active cre (Fig. 7). Expression of YFP in the Synapsin-cre;ephrin-B1 ${ }^{\text {loxP/Y }}$ was much more restricted in the embryonic brain. Ephrin-B1 expression (Fig. 7 , red) in the Synapsin-cre;ephrin-B1 ${ }^{\text {loxP/Y }}$ hippocampus appeared very similar to the ephrin- $B 1^{\text {loxP/Y }}$ controls. However, loss of ephrin-B1 expression was observed in the GFAP-cre;ephrin-B1 ${ }^{\text {loxP/Y }}$ brains throughout the ventricular proliferative zone, including the dentate notch (Fig. 7, asterisk) and in the hippocampus, including the molecular layer above the tertiary matrix (Fig. 7, $\Delta$ ). Of particular interest, loss of ephrin-B1 expression was not observed in the GFAPpositive ridge in the GFAP-cre;ephrin-B1 $1^{\operatorname{lox} / Y}$ mice, indicating that ephrin-B1 expression here does not contribute to formation of the LSB.

\section{Disruption of EphB2 forward signaling reduces Reelin expression around the LSB}

The activity of the GFAP-cre driver illustrated in Figure 7 indicates that there are two possible areas of ephrin-B1 expression that may influence the development of the LSB, namely the molecular layer above the LSB and the ventricular proliferative zone near the dentate notch. The molecular layer has been previously shown to influence DG development. This area, also known as the marginal zone (MZ), contains Cajal-Retzius cells that secrete Reelin, an extracellular matrix protein important for neuronal migration. As loss of Reelin has significant effects on DG morphology (Förster et al., 2002; Frotscher et al., 2003), we investigated its expression within the developing hippocampus and compared with EphB2 and ephrin-B1 expression patterns. We found that Reelin is expressed above the developing suprapyramidal blade in WT mice at E18 and is closely associated with both EphB2 and ephrin-B1, particularly where the LSB will form (Fig. $8 A$ ). EphB2 is intensely expressed below the band of Reelin expression, with some coexpression of EphB2 and Reelin observed, while ephrin-B1 is expressed above the band of Reelin expression.

We next examined Reelin in EphB2 and ephrin-B1 mutant brains collected at E18 and noted an obvious reduced expression in cells directly above where the LSB should form (Fig. $8 B$ ). This decrease in Reelin expression corresponds with the decrease in Sox 2 and nestin- 


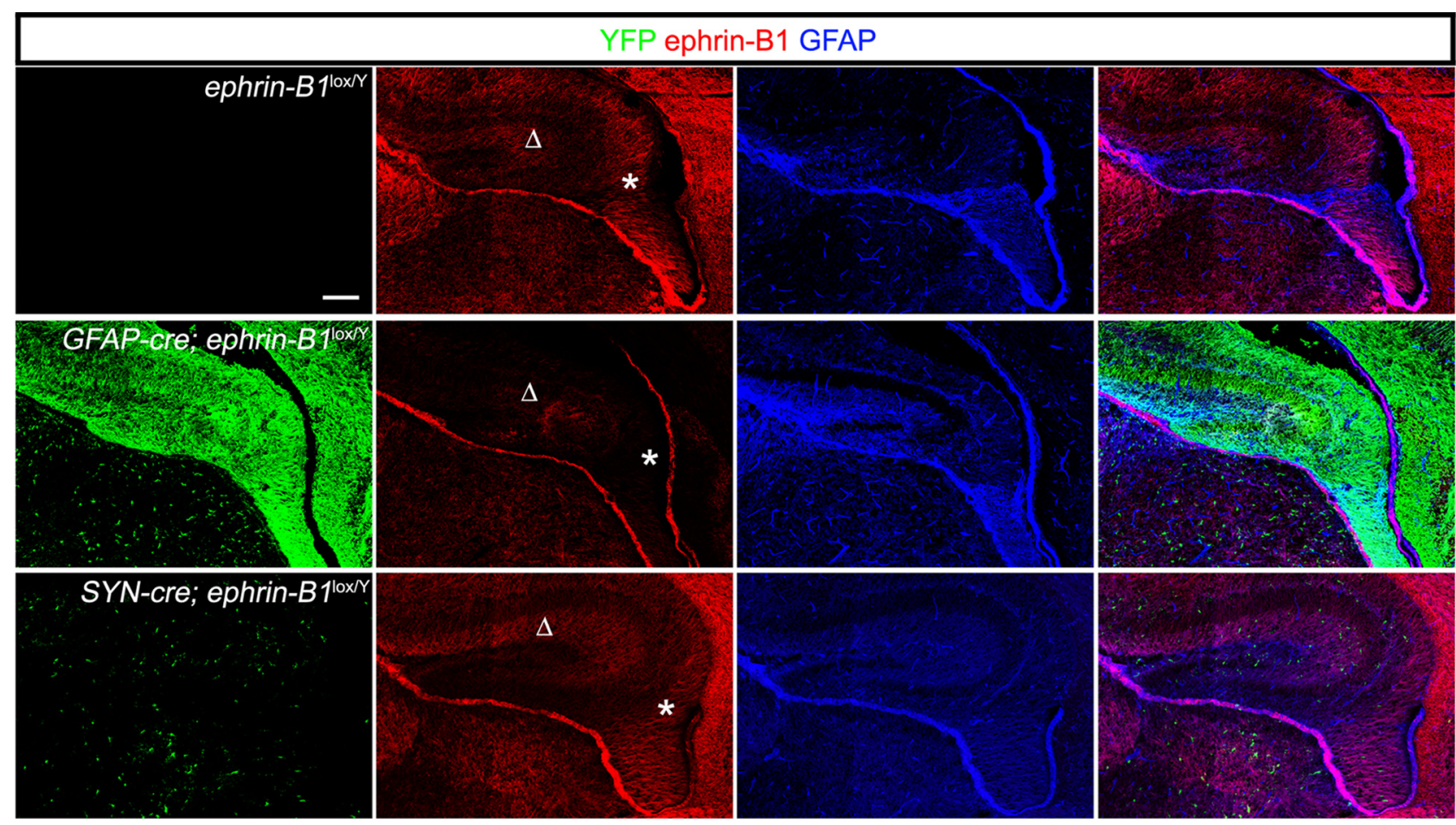

Figure 7. The GFAP-cre driver deletes ephrin-B1 in select areas throughout the developing hippocampus. Shown are, Confocal IF images of the early DG from ephrin-B1 loxP ${ }^{\text {, }}$, GFAP-cre; ephrin-B $7^{\text {loxP } N}$ and Synapsin-cre; ephrin-B1 ${ }^{\text {lox } / Y}$ brains collected at E18 containing rosa-YFP and immunoreacted for YFP (green), ephrin-B1 (red), and GFAP (blue). Deletion of ephrin-B1 using the GFAP-cre driver deletes ephrin-B1 at the ventricular zone near the dentate notch (asterisk) and the area above the developing suprapyramidal blade ( $\Delta$ ), but not in the GFAP-positive ridge. Scale bar, $100 \mu \mathrm{m}$.
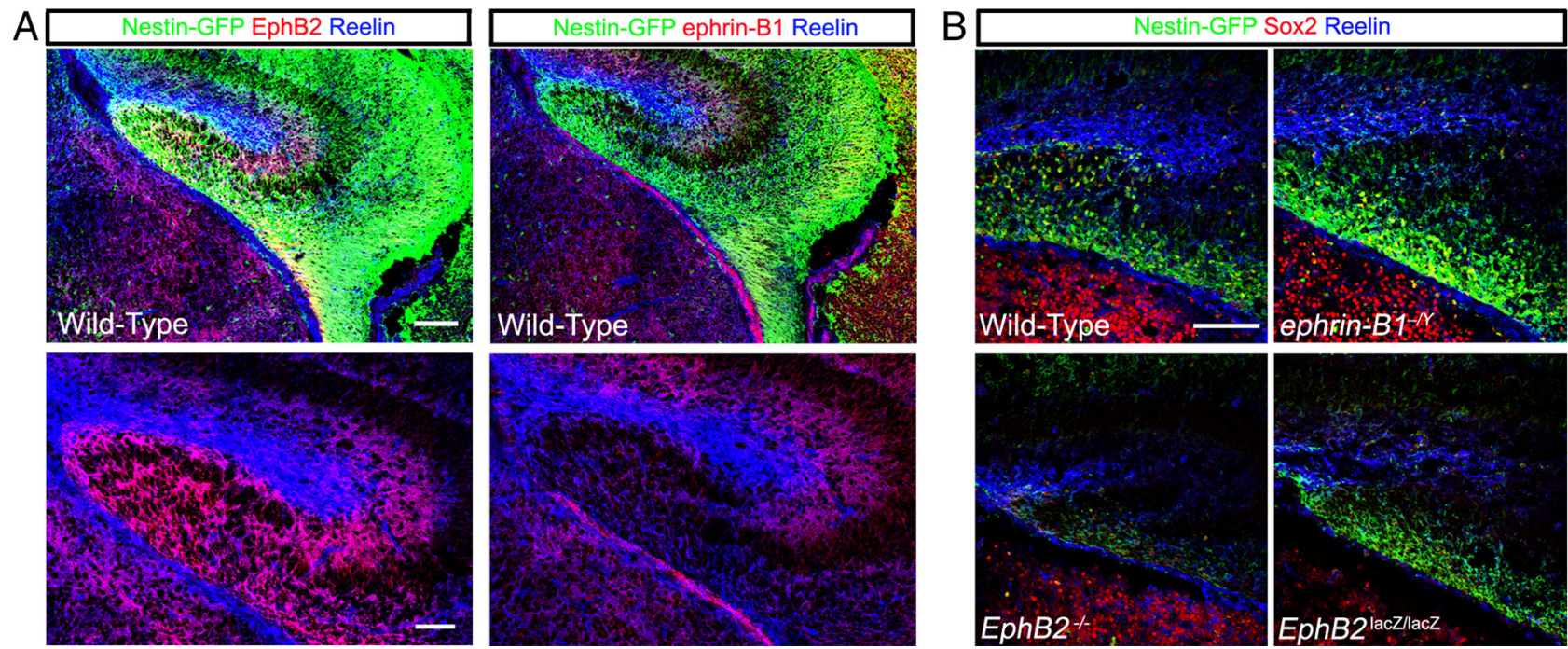

Figure 8. Reduced expression of Reelin above the developing LSB in EphB2 and ephrin-B1 mutants. $A$, Confocal IF images of the hippocampus from WT brains collected at E18 containing the nestin-GFP transgene and immunoreacted for GFP (green), EphB2 or ephrin-B1 (red), and Reelin (blue). Reelin expression in themolecular layer/marginal zone above the developing LSB is closely associated with ephrin-B1 and EphB2 expression. Scale bar, $100 \mu \mathrm{m}, 50 \mu \mathrm{m}$ in expanded image without GFP signal. $\boldsymbol{B}$, Confocal IF images of the DG from WT, ephrin-B1 ${ }^{-N}$, EphB2 ${ }^{-1-}$, and EphB2 ${ }^{\text {lac/lacZ }}$ brains collected at E18 containing the nestin-GFP transgene and immunoreacted for GFP (green), Sox2 (red), and Reelin (blue). Disruption of Eph/ephrin signaling leads to a reduction in Reelin expression in the molecular layer. Scale bar, $100 \mu \mathrm{m}$.

GFP-positive progenitors occupying this area in the mutants. The observation of reduced Reelin expression in the EphB2 ${ }^{\text {lacZ/lacZ }}$ brain demonstrates that EphB2 forward signaling is necessary for robust expression of Reelin in the area of the hippocampus that gives rise to the LSB.

\section{Discussion}

The formation of the DG and the molecules involved in this developmental process are beginning to be illuminated. Here we show that Eph-ephrin signaling contributes to the early development of this structure, as EphB2 tyrosine kinasedependent forward signaling is required for the migration of neural progenitors into the dorsal region of the tertiary matrix to form the LSB. We demonstrate that ephrin-B1 acting as the ligand is also necessary for correct formation of the LSB, and that these molecules likely regulate the formation of the DG at least in part by influencing expression of Reelin in the $\mathrm{MZ}$ area directly above where the LSB will form. 
Reelin is an extracellular matrix molecule expressed by CajalRetzius cells located in the MZ of the hippocampus (Del Río et al., 1997). Loss of Reelin has drastic effects on the structure of the DG as observed in Reeler mutant mice, at least in part by controlling the formation of the radial glial scaffold of the developing DG (Förster et al., 2002; Frotscher et al., 2003). Reelin has also been shown to determine aspects of the migration of DG progenitors from the ventricle to the developing DG (Li et al., 2009). Interpreting the phenotypes observed in the EphB2 and ephrin-B1 mutants, Reelin is likely acting as an attractant to neural progenitors in the tertiary matrix, and loss of Reelin above the dorsal half of the developing DG leads to a failure of neural progenitors to migrate into this area. Interestingly, the effects on DG structure observed in EphB2/ephrin-B1 mutants compared with Reeler mice are strikingly different. Granule neurons in Reeler mice fail to coalesce into densely packed layers and are loosely distributed throughout the developing DG (Drakew et al., 2002), whereas granule neurons in EphB2 forward signaling mutants are selectively absent in the LSB and remain tightly packed throughout the remainder of the DG. This discrepancy may be explained by the observation that Reelin expression is specifically lost above the LSB in EphB2/ephrin-B1 mutant mice, and is still expressed surrounding the other regions of the developing DG.

Although our data strongly suggest that Eph-ephrin signaling in DG development is of primary importance immediately surrounding the developing LSB, we cannot rule out a role for these signaling events at the ventricular proliferative zone. Ephrin-B1 is expressed at a high concentration in the ventricular zone, where both cortical and DG neuron precursors arise (Fig. 4). In an early study involving thymidine labeling during embryonic development of the hippocampus, it was demonstrated that proliferating DG neuron progenitors arise in an area of the lateral ventricles termed the primary dentate neuroepithelium, otherwise known as the dentate notch (Altman and Bayer, 1990a). This area transitions into a secondary matrix, which produces proliferative cells that migrate medially from this ventricular zone subregion to the site of DG formation, termed the tertiary matrix. Previously, it was demonstrated that ephrin-B1 expressed in progenitor cells in the cortical ventricular zone is involved with the maintenance of the progenitor pool in cortical neurogenesis (Qiu et al., 2008). This function was linked to ephrin-B1 reverse signaling, which does not play a role in the DG phenotype described here, as we have analyzed ephrin-B1 reverse signaling mutants (Bush and Soriano, 2009) and did not observe any abnormalities in LSB morphology (data not shown). As the DG neuron progenitors leave the secondary matrix and migrate in a medial direction toward the tertiary matrix, ephrin-B1 expression is lost and EphB2 expression is observed. These EphB2-positive cells then migrate to the tertiary matrix. DG granule layer development occurs in a gradient beginning at the crest and expanding in a lateral direction over time (Altman and Bayer, 1990b). Our analysis of EphB2 and ephrin-B1 mutant mice demonstrated that disruption of EphB2 forward signaling did not lead to a reduction in progenitor numbers in the ventral half of the tertiary matrix, indicating a role in the migration of progenitor cells from the ventral to the dorsal half of the tertiary matrix, and not in the migration from the ventricular zone to the tertiary matrix.

This study has revealed a particularly interesting aspect of Eph-ephrin signaling in the hippocampus, as EphB1 and EphB2 appear to have both overlapping and separate roles in the DG. Both EphB1 and EphB2 control progenitor number throughout the SGZ in the adult brain, and we show that this activity is linked to the PDZ-binding ability of EphB2. However, only loss of the tyrosine kinase activity of EphB2 affected the number of mature granule cell neurons, a phenotype not observed in the EphB1 ${ }^{-/-}$ mutant mice (Chumley et al., 2007). EphB2 plays a major role in development of the DG as the formation of the LSB is disrupted in the embryonic brain. EphB1 does not appear important in the early development of the DG, as genetic deletion of EphB1 does not affect the DG volume. Interestingly, both EphB1 (Chumley et al., 2007) and EphB2 (this study) are expressed on migrating neural progenitors as they migrate to the site of DG development. While we have shown that EphB1 and EphB2 are expressed in the embryonic DG neural progenitors, we have not established levels of expression at the cell membrane. EphB2 could be expressed at a much higher level than EphB1, making it more influential in the early development of the DG than EphB1. Alternatively, EphB1 and EphB2 may transduce somewhat different forward signals to bring about their distinct effects on the migration and proliferation of dentate precursors. This latter possibility has foundations in other studies that show the intracellular signaling domains of EphB1 and EphB2 have very different abilities to mediate the ipsilateral routing of retinal ganglion cell axons despite a high degree of sequence identity between the two receptors (Petros et al., 2009).

The fact that such a specific part of the DG is affected while the remainder of the structure remains relatively normal could have specific effects on hippocampal function. A number of studies have shown a separation of function between the dorsal and the ventral DG. The dorsal DG has been linked to spatial learning and memory (Hunsaker and Kesner, 2008), while the ventral DG has been linked to behavior correlated with anxiety (Eadie et al., 2009). The structure of the adult DG in EphB2 and ephrin-B1 mutants suggests that these mice should have spatial information processing deficits, and yet anxiety behavior should remain relatively unaffected.

As well as the demonstrated effects on Reelin expression, Ephephrin signaling may affect DG morphogenesis via other signaling pathways that have been shown to control the development of the DG (Li and Pleasure, 2007). Elimination of the transcription factors Sox 2 or neurogenin 2 in neural progenitors greatly decreases the size of the DG (Galichet et al., 2008; Favaro et al., 2009). Loss of Draxin, a protein linked to repulsive axon guidance functions, was also shown to cause a decrease in size of the entire DG (Zhang et al., 2010). Mice lacking the chemokine receptor CXCR4 and the ligands SDF- 1 and Cxcl12 were shown to greatly decrease the number of cells that populate the DG (Lu et al., 2002; Li et al., 2009). Likewise, sonic hedgehog signaling is also required for formation of the dentate stem cell niche (Machold et al., 2003). Other signaling molecules have been shown to specifically affect the radial glial scaffold, such as Wnts (Galceran et al., 2000; Zhou et al., 2004). Our analysis of ephrin-B1 knock-out mutant DGs at E18 shows that the GFAP expression around the developing LSB is disrupted. However, unlike Wnt signaling mutants, the majority of the DG is still able to form correctly in the EphB2 and ephrin-B1 mutants with only the LSB affected, indicating that Eph-ephrin and Wnt signaling have separate roles in DG morphogenesis. Interestingly, these two signaling pathways have been linked in regulating the stem cell niche in the intestinal epithelium (Batlle et al., 2002; Holmberg et al., 2006), suggesting the possibility that Wnt and Eph-ephrin signals are common features that dictate stem cell migration and proliferation throughout the body.

It remains to be determined exactly how EphB2 kinasedependent forward signaling affects Reelin expression in the MZ. We observed some coexpression of Reelin and EphB2 in Cajal- 
Retzius cells, suggesting that EpB2 forward signaling may play a cell-autonomous role in the expression and secretion of Reelin once activated by the ephrin-B1-positive cells surrounding the MZ. Alternatively, EphB2 activity may determine the migration of Cajal-Retzius cells into the MZ, and loss of forward signaling would result in fewer numbers of Cajal-Retzius cells above the LSB. Interestingly, we show that EphB2 and ephrin-B1 are expressed in opposing gradients surrounding Reelin, with EphB2 highly expressed below and ephrin-B1 highly above the observed Reelin expression in the MZ. Presumably, Eph-ephrin signaling is strongest at the point where these gradients overlap, immediately next to the cluster of Reelin above the developing LSB. These data suggest that Reelin expression may require a gradient of Ephephrin signaling strength.

\section{References}

Abrous DN, Koehl M, Le Moal M (2005) Adult neurogenesis: from precursors to network and physiology. Physiol Rev 85:523-569.

Altman J, Bayer SA (1990a) Mosaic organization of the hippocampal neuroepithelium and the multiple germinal sources of dentate granule cells. J Comp Neurol 301:325-342.

Altman J, Bayer SA (1990b) Migration and distribution of two populations of hippocampal granule cell precursors during the perinatal and postnatal periods. J Comp Neurol 301:365-381.

Alvarez-Buylla A, Seri B, Doetsch F (2002) Identification of neural stem cells in the adult vertebrate brain. Brain Res Bull 57:751-758.

Batlle E, Henderson JT, Beghtel H, van den Born MM, Sancho E, Huls G, Meeldijk J, Robertson J, van de Wetering M, Pawson T, Clevers H (2002) Beta-catenin and TCF mediate cell positioning in the intestinal epithelium by controlling the expression of EphB/ephrinB. Cell 111:251-263.

Bush JO, Soriano P (2009) Ephrin-B1 regulates axon guidance by reverse signaling through a PDZ-dependent mechanism. Genes Dev 23:15861599.

Chumley MJ, Catchpole T, Silvany RE, Kernie SG, Henkemeyer M (2007) EphB receptors regulate stem/progenitor cell proliferation, migration, and polarity during hippocampal neurogenesis. J Neurosci 27:1348113490.

Davy A, Aubin J, Soriano P (2004) Ephrin-B1 forward and reverse signaling are required during mouse development. Genes Dev 18:572-583.

de Bergeyck V, Naerhuyzen B, Goffinet AM, Lambert de Rouvroit C (1998) A panel of monoclonal antibodies against reelin, the extracellular matrix protein defective in reeler mutant mice. J Neurosci Methods 82:17-24.

Del Río JA, Heimrich B, Borrell V, Förster E, Drakew A, Alcántara S, Nakajima K, Miyata T, Ogawa M, Mikoshiba K, Derer P, Frotscher M, Soriano E (1997) A role for Cajal-Retzius cells and reelin in the development of hippocampal connections. Nature 385:70-74.

Deng W, Aimone JB, Gage FH (2010) New neurons and new memories: how does adult hippocampal neurogenesis affect learning and memory? Nat Rev Neurosci 11:339-350.

Doetsch F (2003) The glial identity of neural stem cells. Nat Neurosci 6:1127-1134

Drakew A, Deller T, Heimrich B, Gebhardt C, Del Turco D, Tielsch A, Förster E, Herz J, Frotscher M (2002) Dentate granule cells in reeler mutants and VLDLR and ApoER2 knockout mice. Exp Neurol 176:12-24.

Eadie BD, Zhang WN, Boehme F, Gil-Mohapel J, Kainer L, Simpson JM, Christie BR (2009) Fmrl knockout mice show reduced anxiety and alterations in neurogenesis that are specific to the ventral dentate gyrus. Neurobiol Dis 36:361-373.

Favaro R, Valotta M, Ferri AL, Latorre E, Mariani J, Giachino C, Lancini C, Tosetti V, Ottolenghi S, Taylor V, Nicolis SK (2009) Hippocampal development and neural stem cell maintenance require Sox2-dependent regulation of Shh. Nat Neurosci 12:1248-1256.

Förster E, Tielsch A, Saum B, Weiss KH, Johanssen C, Graus-Porta D, Müller U, Frotscher M (2002) Reelin, Disabled 1, and beta 1 integrins are required for the formation of the radial glial scaffold in the hippocampus. Proc Natl Acad Sci U S A 99:13178-13183.

Frotscher M, Haas CA, Förster E (2003) Reelin controls granule cell migration in the dentate gyrus by acting on the radial glial scaffold. Cereb Cortex 13:634-640.
Galceran J, Miyashita-Lin EM, Devaney E, Rubenstein JL, Grosschedl R (2000) Hippocampus development and generation of dentate gyrus granule cells is regulated by LEF1. Development 127:469-482.

Galichet C, Guillemot F, Parras CM (2008) Neurogenin 2 has an essential role in development of the dentate gyrus. Development 135:2031-2041.

Genander M, Halford MM, Xu NJ, Eriksson M, Yu Z, Qiu Z, Martling A, Greicius G, Thakar S, Catchpole T, Chumley MJ, Zdunek S, Wang C, Holm T, Goff SP, Pettersson S, Pestell RG, Henkemeyer M, Frisén J (2009) Dissociation of EphB2 signaling pathways mediating progenitor cell proliferation and tumor suppression. Cell 139:679-692.

Henkemeyer M, Orioli D, Henderson JT, Saxton TM, Roder J, Pawson T, Klein R (1996) Nuk controls pathfinding of commissural axons in the mammalian central nervous system. Cell 86:35-46.

Holmberg J, Genander M, Halford MM, Annerén C, Sondell M, Chumley MJ, Silvany RE, Henkemeyer M, Frisén J (2006) EphB receptors coordinate migration and proliferation in the intestinal stem cell niche. Cell 125:1151-1163.

Hunsaker MR, Kesner RP (2008) Evaluating the differential roles of the dorsal dentate gyrus, dorsal CA3, and dorsal CA1 during a temporal ordering for spatial locations task. Hippocampus 18:955-964.

Kee N, Teixeira CM, Wang AH, Frankland PW (2007) Preferential incorporation of adult-generated granule cells into spatial memory networks in the dentate gyrus. Nat Neurosci 10:355-362.

Li G, Pleasure SJ (2007) Genetic regulation of dentate gyrus morphogenesis. Prog Brain Res 163:143-152.

Li G, Pleasure SJ (2010) Ongoing interplay between the neural network and neurogenesis in the adult hippocampus. Curr Opin Neurobiol 20:126133.

Li G, Kataoka H, Coughlin SR, Pleasure SJ (2009) Identification of a transient subpial neurogenic zone in the developing dentate gyrus and its regulation by Cxcl12 and reelin signaling. Development 136:327-335.

Lu M, Grove EA, Miller RJ (2002) Abnormal development of the hippocampal dentate gyrus in mice lacking the CXCR4 chemokine receptor. Proc Natl Acad Sci U S A 99:7090-7095.

Machold R, Hayashi S, Rutlin M, Muzumdar MD, Nery S, Corbin JG, GritliLinde A, Dellovade T, Porter JA, Rubin LL, Dudek H, McMahon AP, Fishell G (2003) Sonic hedgehog is required for progenitor cell maintenance in telencephalic stem cell niches. Neuron 39:937-950.

Parrinello S, Napoli I, Ribeiro S, Digby PW, Fedorova M, Parkinson DB, Doddrell RD, Nakayama M, Adams RH, Lloyd AC (2010) EphB signaling directs peripheral nerve regeneration through Sox2-dependent Schwann cell sorting. Cell 143:145-155.

Petros TJ, Shrestha BR, Mason C (2009) Specificity and sufficiency of EphB1 in driving the ipsilateral retinal projection. J Neurosci 29:3463-3474.

Qiu R, Wang X, Davy A, Wu C, Murai K, Zhang H, Flanagan JG, Soriano P, Lu Q (2008) Regulation of neural progenitor cell state by ephrin-B. J Cell Biol 181:973-983.

van Praag H, Schinder AF, Christie BR, Toni N, Palmer TD, Gage FH (2002) Functional neurogenesis in the adult hippocampus. Nature 415:10301034

Yu TS, Dandekar M, Monteggia LM, Parada LF, Kernie SG (2005) Temporally regulated expression of Cre recombinase in neural stem cells. Genesis 41:147-153.

Zhang S, Su Y, Shinmyo Y, Islam SM, Naser IB, Ahmed G, Tamamaki N, Tanaka H (2010) Draxin, a repulsive axon guidance protein, is involved in hippocampal development. Neurosci Res 66:53-61.

Zhao C, Teng EM, Summers RG Jr, Ming GL, Gage FH (2006) Distinct morphological stages of dentate granule neuron maturation in the adult mouse hippocampus. J Neurosci 26:3-11.

Zhao C, Deng W, Gage FH (2008) Mechanisms and functional implications of adult neurogenesis. Cell 132:645-660.

Zhou CJ, Zhao C, Pleasure SJ (2004) Wnt signaling mutants have decreased dentate granule cell production and radial glial scaffolding abnormalities. J Neurosci 24:121-126.

Zhu Y, Romero MI, Ghosh P, Ye Z, Charnay P, Rushing EJ, Marth JD, Parada LF (2001) Ablation of NF1 function in neurons induces abnormal development of cerebral cortex and reactive gliosis in the brain. Genes Dev 15:859-876.

Zhuo L, Theis M, Alvarez-Maya I, Brenner M, Willecke K, Messing A (2001) hGFAP-cre transgenic mice for manipulation of glial and neuronal function in vivo. Genesis 31:85-94. 